\title{
Grain Refining of Magnesium Welds by Arc Oscillation
}

\author{
T. Yuan ${ }^{a}$, Z. Luo ${ }^{a}$ and S. Kou ${ }^{b}$ \\ ${ }^{a}$ School of Materials Science and Engineering, Tianjin University, Tianjin 300072, China \\ ${ }^{\mathrm{b}}$ Department of Materials Science and Engineering, University of Wisconsin, Madison, \\ WI 53706, USA
}

\begin{abstract}
Grain refining is known to improve the solidification-cracking resistance and mechanical properties of welds. Mg alloys are increasingly used for vehicle weight reduction. The present study was conducted to grain refine $\mathrm{Mg}$ welds by arc oscillation, which has not been investigated so far. First, significant grain refining was demonstrated by transverse arc oscillation. The effects of oscillation amplitude, oscillation frequency and torch travel speed on grain refining were shown. The effect of the alloy composition on grain refining was also demonstrated. Second, by using an overlap welding procedure, the grain refining mechanism was identified as dendrite fragmentation. Third, cooling curves recorded during welding showed that transverse arc oscillation caused reheating during solidification, which has been shown in casting/solidification to cause dendrite fragmentation by melting off dendrite arms. The cooling curves also showed that transverse arc oscillation significantly reduced the temperature gradient $G$ along the torch travel direction, which suggested constitutional supercooling was increased. Thus, transverse arc oscillation not only caused dendrite fragmentation but also increased constitutional supercooling to help dendrite fragments survive and grow into fine equiaxed grains. Dendrite fragmentation by remelting, instead of mechanical breakup, of dendrites was discussed in the context of welding.
\end{abstract}




\section{Introduction}

In welding $\mathrm{Al}$ alloys by gas-tungsten arc welding (GTAW), which is also called tungsten inert gas (TIG) welding, the grain structure in the fusion zone can be manipulated by magnetically oscillating the arc during welding. This was first demonstrated by Kou and Le [1-3], who used magnetic arc oscillation, either transverse or circular, to create grain structures that significantly improved both the resistance to solidification cracking during welding and the mechanical properties of the resultant welds. Subsequent studies on Al alloys by other investigators [4-8] confirmed the work of Kou and Le [1-3]. More recently, magnetic arc oscillation was also used in GTAW of steel [9] and Ni alloys [10, 11].

By quenching the weld pool and its surrounding area with ice water during GTAW of $\mathrm{Al}$ alloys, Kou and Le [12] preserved the development of microstructure during welding. Three types of microstructure were preserved and revealed clearly: partially melted grains around the weld pool, dendrites behind the weld pool, and heterogeneous nuclei inside the weld pool. Based on them, the microstructure around the pool boundary was proposed as shown schematically in Fig. 1. Each type of microstructure can lead to a different mechanism for nucleation of new grains in the fusion zone, that is, grain detachment, dendrite fragmentation or heterogeneous nucleation [12]. These new grains grow ahead of and can thus block off the columnar grains that grow originally from the fusion boundary by epitaxial growth [13]. The more new grains are, the wider the band of equiaxed grains in the resultant fusion zone.

The use of Mg alloys for vehicle weight reduction has increased significantly recently [14-16]. So far, GTAW is the most widely used arc welding process for $\mathrm{Mg}$ alloys 
because of the excellent weld quality, though significant advancements have been recently made to improve the quality of $\mathrm{Mg}$ welds made by gas-metal arc welding (GMAW) [17-19]. There have been few studies on grain refining in Mg welds, much less than those on Al welds. Babu and Cross [20] grain refined AZ31 Mg by pulsation of alternating current (AC) using an advanced GTAW power source. Tao et al. [21] grain refined AZ31 Mg and AZ91 Mg by ultrasonic stirring of the weld pool. Grain refining of Mg welds by arc oscillation has not been investigated so far. Ram et al. [22] pointed out that arc oscillation worked effectively for some materials but not for other materials. It is unclear if arc oscillation can grain refine $\mathrm{Mg}$ welds effectively.

The present study investigated grain refining of $\mathrm{Mg}$ welds by transverse arc oscillation. This is because, as mentioned previously, the use of $\mathrm{Mg}$ alloys has been increasing rapidly but grain refining of $\mathrm{Mg}$ welds has not been studied much. The purpose was to demonstrate that significant grain refining could be achieved by transverse arc oscillation, identify the grain refining mechanism and explain how arc oscillation help the mechanism achieve grain refining.

\section{Experimental Procedure}

The magnetic arc oscillator used in the present study was a Model 90A arc pattern control along with a 4613A magnetic probe, both manufactured by Cyclomatic Industries, San Diego, CA, which was subsequently taken over by JetLine Engineering. The magnetic probe was in the form of a short cylinder, with a round hole along its axis to allow mounting around a gas-tungsten arc welding torch. The welding torch itself was mounted on a carriage that moved on a track at a constant predetermined speed. The four 
poles of the magnetic probe, $90^{\circ}$ apart, were positioned to surround the tip of the tungsten electrode. Two opposite poles were lined up normal to the torch travel direction and activated to cause transverse arc oscillation. The magnetic arc oscillator was designed to provide arc oscillation at an amplitude equal to the arc length, though amplitudes lower than this maximum one can also be selected. Thus, with a $2 \mathrm{~mm}$ arc length, for instance, the amplitude of arc oscillation could be adjusted between 0 and $2 \mathrm{~mm}$. The minimum oscillation frequency provided by the magnetic arc oscillator was $1 \mathrm{~Hz}$ and the maximum $50 \mathrm{~Hz}$.

Two commercial $\mathrm{Mg}$ alloys were studied. The first one was AZ31 $\mathrm{Mg}$, the most widely used Mg wrought alloy. It was manufactured by Magnesium Elektron in the form for $1.6 \mathrm{~mm}$ sheets and its composition is shown in Table 1. The second $\mathrm{Mg}$ alloy was AZ91 Mg, the most widely used $\mathrm{Mg}$ casting alloy. It was manufactured by US Magnesium in the form of ingots and its composition is also shown in Table 1.

The workpiece was prepared in the form of a $102 \mathrm{~mm}$ x $102 \mathrm{~mm}$ x $1.6 \mathrm{~mm}$ sheet for welding. It was bead-on-plate welded without filler metal by gas-tungsten arc welding (GTAW) along the centerline of the workpiece. GTAW was conducted with direct current electrode negative (DCEN). The electrode, $3.2 \mathrm{~mm}$ in diameter, had a $50^{\circ}$ included angle at the tip. The arc gap was $2 \mathrm{~mm}$ and the shielding gas pure Ar at $1 \mathrm{~m}^{3} / \mathrm{h}(16.5 \mathrm{~L} / \mathrm{min})$. The welding conditions are shown in Table 2 .

The cooling curve was recorded during welding, with and without arc oscillation. A K-type thermocouple with a stainless steel sheath of $0.5 \mathrm{~mm}$ outer diameter was used. With a mechanical device the thermocouple tip was plunged into the weld pool at a short 
distance behind the welding arc along the centerline of the weld pool. The cooling curves were recorded with a computer-based data acquisition system, the data acquisition frequency being $20 \mathrm{~Hz}$.

In order to identify which mechanism was responsible for grain refining in a weld made with transverse arc oscillation, the overlap welding procedure that Kou and Le [12] developed for identifying nucleation mechanisms in $\mathrm{Al}$ welds was used. This procedure is illustrated in Fig. 2. The weld in which the nucleation mechanism of equiaxed grains is to be identified is called the test weld. Before the test weld was made, a wider and shorter weld was made, called the preweld. After the preweld cooled to the room temperature, the test weld was made to run into and overlap with the preweld. The test weld was a 1-pass weld made with grain refining by transverse arc oscillation at $1 \mathrm{~Hz}$ oscillation frequency and $2 \mathrm{~mm}$ oscillation amplitude. The preweld was made without arc oscillation, either single- or multiple-pass.

In Fig. 2a the preweld is a single-pass weld made without arc oscillation. If coarse columnar grains dominate its bulk fusion zone, they are interlocked firmly with one another, unable to be detached and carried as small grains into the weld pool of the test weld. Rather, they grow into the test weld by epitaxial growth [13]. Thus, grain refining can be expected to stop after the test weld runs into the preweld. If this does happen, grain detachment is likely the grain refining mechanism in the test weld outside the preweld. For grains to be detached from the partially melted zone, they need to be loosely held small grains that are completely surrounded by the liquid in the partially melted zone so that they can be swept by fluid flow into the weld pool, such as in the case of $7004 \mathrm{Al}$ 
alloy [23]. However, if grain refining continues after the test weld runs into the preweld, either heterogeneous nucleation or dendrite fragmentation is likely to be the grain refining mechanism as illustrated in Fig. $2 b$.

In $\mathrm{Al}$ ingot casting an $\mathrm{Al}-\mathrm{Ti}-\mathrm{B}$ type master alloy containing $\mathrm{Al}_{3} \mathrm{Ti}$ and $\mathrm{TiB}_{2}$ particles is added to liquid $\mathrm{Al}$ as a grain refiner. $\mathrm{Al}_{3}$ Ti particles can nucleate solid $\mathrm{Al}$ effectively, but it can dissolve in liquid $\mathrm{Al}$ despite its very high melting point of about $1350^{\circ} \mathrm{C}$. $\mathrm{TiB}_{2}$ can also nucleate solid Al effectively and it dissolves in liquid Al much more slowly, but it can be easily contaminated by impurities to become ineffective unless covered with a thin layer of $\mathrm{Al}_{3} \mathrm{Ti}[24,25]$. Even if the understanding of the nucleation mechanism may still improve, the practice has been to solidify the Al melt shortly after the addition of the grain refiner. After casting and rolling down to thin sheets, these particles are still present and can they can act as heterogeneous nuclei again during weld pool solidification [12, 13]. To dissolve these particles or make them ineffective, a preweld can be made with multiple passes to melt back and forth multiple times. With significantly fewer effective nuclei available for nucleation, fine equiaxed grains should decrease or even disapper after the test weld runs into the preweld. If this does occur, heterogeneous nucleation is likely the grain refining mechanism in the test weld outside the preweld as illustrated in Fig. 2c. However, if grain refining remains unchanged or even increases after the test weld runs into the preweld, dendrite fragmentation is the likely grain refining mechanism as illustrated in Fig. 2d. The overlap welding procedure has been verified against $\mathrm{Al}$ welds [12]. By using a procedure similar to that shown in Fig. 2a, Pearce and Kerr [23] identified grain detachment as the grain refining mechanism in $7004 \mathrm{Al}$ welds made by 
stirring of the weld pool with a magnetic coil from below.

The overlapping welding conditions are shown in Table 3. For AZ31 Mg the welding current was $75 \mathrm{~A}$ for the test weld and $100 \mathrm{~A}$ for the preweld. The travel speed was 3.18 $\mathrm{mm} / \mathrm{s}$ in both cases. After welding, the AZ31 Mg welds were cut, ground below the top surface, polished and etched. The etching solution was $10 \mathrm{ml}$ glacial acetic acid, $10 \mathrm{ml}$ distilled water, $6 \mathrm{~g}$ picric acid and $100 \mathrm{ml}$ anhydrous ethyl alcohol. Micrographs were taken with polarized light to show different grains in different colors [26]. As grains in AZ31 welds can be revealed clearly by color etching, and there was no need to use EBSD to show the grains in color. Although EBSD can reveal the angle of misorientation between two neighboring grains [10], optical micrographs have been widely used for studying grain refining for decades both in welding and casting $[13,27]$. The AZ91 Mg welds were subjected to a $\mathrm{T} 4$ heat treatment to dissolve the $\mathrm{Mg}_{17} \mathrm{Al}_{12}$ phase along grain boundaries (and within grains) and then quenched. This procedure was reported to bring out grain boundaries clearly without grain growth [28]. The heat treated specimens were then cut, ground below the top surface, polished and etched with a solution of $20 \mathrm{ml}$ glacial acetic acid, $10 \mathrm{ml}$ distilled water, and $100 \mathrm{ml}$ anhydrous ethyl alcohol. Details of the metallographic procedure for welds of both AZ31 $\mathrm{Mg}$ and AZ91 $\mathrm{Mg}$ have been described previously [21] and will not be repeated here.

\section{Results and Discussion}

An example of a weld made with transverse arc oscillation is shown in Fig. 3. The $\mathrm{Mg}$ vapor deposited on the weld surface beyond Ar shielding was oxidized and became dark in color. Arc oscillation caused a periodic pattern in the dark deposit. 


\subsection{Effects of oscillation amplitude, oscillation frequency and travel speed}

As mentioned previously, a typical magnetic arc oscillator such as that used in the present study is designed to provide a maximum amplitude of oscillation equal to the arc length. Since the $2 \mathrm{~mm}$ arc length used in the present study is typical in gas-tungsten arc welding, the maximum $2 \mathrm{~mm}$ oscillation amplitude used in the present study is not just a particular oscillation condition.

Fig. 4 shows the effect of the amplitude of arc oscillation on grain refining in AZ31 $\mathrm{Mg}$ welds. The torch travel speed is $3.18 \mathrm{~mm} / \mathrm{s}$. Without arc oscillation, coarse columnar grains exist throughout the fusion zone. With transverse arc oscillation at the frequency of $1 \mathrm{~Hz}$, significant grain refining occurs at $1 \mathrm{~mm}$ amplitude of oscillation. Increasing the amplitude to $2 \mathrm{~mm}$ seems to cause some additional grain refining. Increasing the amplitude of arc oscillation can be expected to disturb weld pool solidification to a greater extent to cause more grain refining. However, the effect of amplitude on grain refining seems to level off beyond a certain amplitude.

Fig. 5 shows the effect of oscillation frequency on grain refining in AZ31 Mg welds. The amplitude of oscillation is kept constant at $2 \mathrm{~mm}$, and the torch travel speed 3.18 $\mathrm{mm} / \mathrm{s}$. As shown in Fig. 5, grains are very fine at 1 and $13 \mathrm{~Hz}$ but become significantly coarser at $25 \mathrm{~Hz}$ and very coarse at $50 \mathrm{~Hz}$ (similar to no arc oscillation as shown previously in Fig. 4a). As mentioned previously, the minimum frequency of the magnetic arc oscillator used in the present study was $1 \mathrm{~Hz}$ (maximum $50 \mathrm{~Hz}$ ). Thus, in the frequency range of 1 to $50 \mathrm{~Hz}$, the optimum frequency is $1 \mathrm{~Hz}$. 
A low frequency near $1 \mathrm{~Hz}$ is typical for transverse arc oscillation and not just a particular oscillation condition selected in the present study. Low-frequency transverse arc oscillation has been found particularly effective for reducing the grain size in welds. For instance, Ram et al. [22] found 1 and $2.5 \mathrm{~Hz}$ produced effective grain refining in $2090 \mathrm{Al}$ while $7.5 \mathrm{~Hz}$ and above produced little grain refining. Biradar et al. [7] grain refined Al-Mg-Si welds by transverse arc oscillation at about $1 \mathrm{~Hz}$. Kou and Le [1] grain refined $5052 \mathrm{Al}$ welds by transverse arc oscillation at $1 \mathrm{~Hz}$ frequency and $2 \mathrm{~mm}$ amplitude. With a low frequency the temperature and convection fields in the weld pool can have more time to respond to the oscillating arc and vary periodically to cause grain refining [22]. As will be shown subsequently by the cooling curve (in Fig. 14b), at $1 \mathrm{~Hz}$ reheating can occur during cooling to remelt dendrites to cause dendrite fragmentation and hence grain refining in AZ31 Mg. A frequency such as $50 \mathrm{~Hz}$ does not allow time for significant reheating to occur during cooling.

Fig. 6 shows the effect of torch travel speed on grain refining in AZ31 Mg welds. The amplitude of oscillation is kept constant at $2 \mathrm{~mm}$, and the frequency $1 \mathrm{~Hz}$. The torch travel speed is raised from 2.12 to 3.18 to $4.23 \mathrm{~mm} / \mathrm{s}$. As shown, grain refining seems not very sensitive to the torch travel speed. Increasing the torch travel speed is known to increase the extent of constitutional supercooling [13]. Either this effect was small as compared to the constitutional supercooling caused by transverse arc oscillation or dendrite fragmentation caused by transverse arc oscillation, both of which will be discussed subsequently. In grain refining of AZ31 Mg welds by ultrasonic stirring of the weld pool, grain refining was not very sensitive to the travel speed, either [21]. 
Fig. 7 shows the effect of the amplitude of arc oscillation on grain refining in AZ91 Mg welds. The torch travel speed is $2.75 \mathrm{~mm} / \mathrm{s}$. Without arc oscillation, columnar grains are visible near the weld centerline (left-hand side of the photo). With transverse arc oscillation at $1 \mathrm{~Hz}$ frequency and $1 \mathrm{~mm}$ amplitude, significant grain refining can be seen especially near the weld centerline, where the coarse columnar grains become significantly smaller. With the oscillation frequency still kept at $1 \mathrm{~Hz}$ but the amplitude increased further to 1.5 and $2 \mathrm{~mm}$, no significant further grain refining can be seen though some grains became smaller in size.

Fig. 8 shows the effect of the frequency of arc oscillation on grain refining in AZ91 Mg welds. The torch travel speed is $2.75 \mathrm{~mm} / \mathrm{s}$, and the oscillation amplitude $2 \mathrm{~mm}$. As oscillation frequency is raised from 1 to 13 and $50 \mathrm{~Hz}$, the extent of grain refining remains essentially unchanged. Thus, grain refining in AZ91 Mg seems not sensitive to the oscillation frequency.

Fig. 9 shows the effect of torch travel speed on grain refining in AZ91 Mg welds. The amplitude of oscillation is kept constant at $2 \mathrm{~mm}$, and the frequency $1 \mathrm{~Hz}$. As the torch travel speed is raised from 2.75 to 4.23 and $6.35 \mathrm{~mm} / \mathrm{s}$, the extent of grain refining does not appear to change much. Thus, grain refining of AZ91 Mg welds by transverse arc oscillation seems not very sensitive to the torch travel speed. In grain refining of AZ91 Mg welds by ultrasonic stirring of the weld pool, grain refining was not very sensitive to the travel speed, either [21].

\subsection{Effect of alloy composition}


The welds of AZ31 Mg and those of AZ91 Mg have two similarities. First, with significant grain refining can occur with arc oscillation at $1 \mathrm{~Hz}$ frequency and $1 \mathrm{~mm}$ amplitude. Second, no significant further grain refining occurs when the oscillation frequency is raised beyond $1 \mathrm{~mm}$. Third, grain refining is not very sensitive to the travel speed. However, there is a very significant difference between the welds of the two $\mathrm{Mg}$ alloys, that is, AZ91 Mg has a much greater tendency to form equiaxed grains than AZ31 Mg. Without arc oscillation, many equiaxed grains can still exist in an AZ91 Mg weld (Fig. 7a) but not in an AZ31 Mg weld (Fig. 4a). Equiaxed grains can still exist throughout an AZ91 Mg weld beyond $13 \mathrm{~Hz}$ oscillation frequency (Fig. 8) but not an AZ31 Mg weld (Fig. 5).

The greater tendency of AZ91 Mg to form equiazed grains than AZ31 $\mathrm{Mg}$ can be explained as follows. As compared to AZ31 Mg, AZ91 Mg has much more Al to provide extra constitutional supercooling to help small solid particles, once they form in the weld pool, to survive and grow into equiaxed grains [13]. StJohn et al. [29] showed that the grain size $d$ measured in castings of Mg alloys can be related to the alloy composition as follows:

$$
\begin{aligned}
& d=a+\frac{b}{Q} \\
& Q=\Sigma_{1}^{i} m_{L i} C_{o i}\left(k_{i}-1\right)
\end{aligned}
$$

where $a$ and $b$ are constants and $m_{L i}, C_{o i}$ and $k_{i}$ are the liquidus slope, concentration and equilibrium segregation coefficient of component $i$ in the alloy. The growth restriction factor $Q$ was shown to be the rate of development of constitutional supercooling $\Delta T_{c}$ with respect to the fraction solid $f_{S}$ at the beginning of growth. As compared to AZ31 Mg, 
AZ91 Mg has a much higher $\mathrm{Al}$ content and hence growth restriction factor $Q$ to keep the grain size $d$ small.

\subsection{Identification of grain refining mechanism}

Fig. 10 shows the solidification path of AZ31 Mg, i.e., the curves of temperature $T v s$. fraction solid $f_{S}$. It was calculated using the thermodynamic software Pandat [30] and $\mathrm{Mg}$ database PanMagnesium [31] of CompuTherm, LLC in Madison, WI. Since AZ31 Mg contains both $\mathrm{Al}$ (about 3 wt \%) and $\mathrm{Mn}$ (about $0.6 \mathrm{wt} \%$ ), some $\mathrm{Al}_{8} \mathrm{Mn}_{5}$ particles exist in AZ31 Mg sheets before welding. This has been verified by EDS (energy dispersive x-ray spectrometry) and SEM (scanning electron microscopy) in the same AZ31 Mg sheets used in the present study [32]. No other particles were found. Fig. 8 shows that $\mathrm{Al}_{8} \mathrm{Mn}_{5}$ forms from the melt at $674^{\circ} \mathrm{C}$, just $42^{\circ} \mathrm{C}$ before the primary $\mathrm{Mg}$-rich phase $(\mathrm{Mg})$ does at $632^{\circ} \mathrm{C}$. This suggests two things. First, $\mathrm{Al}_{8} \mathrm{Mn}_{5}$ particles in the workpiece melt completely during welding. This is different from the $\mathrm{TiB}_{2}$ and $\mathrm{Al}_{3} \mathrm{Ti}$ particles in $\mathrm{Al}$ alloys, which do not melt in the weld pool unless welded repeatedly for several times. Second, since solid $\mathrm{Al}_{8} \mathrm{Mn}_{5}$ particles form in the melt before $(\mathrm{Mg})$ does, it is possible for $(\mathrm{Mg})$ to nucleate on these particles during cooling. To be effective for heterogeneous nucleation a solid particle needs to have, for example, a low wetting angle by the melt, which is favored by good lattice matching and hence a low-energy interface between the particle and the primary solid phase.

Now the grain refining mechanism of Weld \#4 in Fig. $4 d$ will be identified. In the overlap weld shown in Fig. 11, the test weld (Weld \#19) was made with transverse arc oscillation at $1 \mathrm{~Hz}$ frequency and $2 \mathrm{~mm}$ amplitude in a single pass. The preweld (Weld 
\#18), on the other hand, was made without arc oscillation in a single pass. As shown in Fig. 11a, in the test weld outside the preweld fine equiaxed grains dominate except for the fine columnar grains along the external and internal fusion boundaries.

As shown in Fig. 11b, fine equiaxed grains dominate in the test weld inside the preweld, smaller in size and greater in number than those in the test weld outside the preweld. Thus, the grain size of the test weld is reduced as it enters the preweld. This clearly is more consistent with the mechanism shown in Fig. 2b than that in Fig. 2a. Thus, the mechanism for the formation of fine equiaxed grains in Weld \#4 (Fig. 4d) is not grain detachment. It is either heterogeneous nucleation or dendrite fragmentation. In fact, as shown in Fig. 11b, the grains in the preweld (Weld \#18) are very coarse (similar to those in Weld \#1 in Fig. 4a). These grains are well connected to neighboring coarse grains in the preweld and thus are unlikely to be detached and carried as small grains into the pool of the test weld to form the fine equiaxed grains in Fig. 11b.

To further identify the grain refining mechanism, the preweld was prepared by melting back and forth six times to dissolve heterogeneous nuclei that may exist well above the liquidus temperature. As mentioned previously, $\mathrm{Al}_{8} \mathrm{Mn}_{5}$ particles in the $\mathrm{AZ} 31$ $\mathrm{Mg}$ workpiece dissolve in the weld pool completely above $674^{\circ} \mathrm{C}$, which is just $42^{\circ} \mathrm{C}$ above the liquidus temperature of $\mathrm{AZ} 31 \mathrm{Mg}$. Although according to its nominal composition, AZ31 Mg contains $\mathrm{Mg}, \mathrm{Al}$ and $\mathrm{Zn}$, small amounts of other elements such as $\mathrm{Mn}, \mathrm{Fe}, \mathrm{Si}, \mathrm{Ni}, \mathrm{Cu}$ and $\mathrm{Be}$ can also exist [33]. Compounds of a high melting point between $\mathrm{Mg}$ and these elements are not expected, but repeated melting was still conducted to rule out the possibility of high temperature particles acting as heterogeneous 
nuclei. In the overlap weld shown in Fig. 12, the test weld (Weld \#21) was still made with transverse arc oscillation at $1 \mathrm{~Hz}$ frequency and $2 \mathrm{~mm}$ amplitude but the preweld (Weld \#20) was made without arc oscillation in six passes. The test weld shows finer grains inside the preweld than outside. This difference is more consistent with the mechanism shown in Fig. 2d than that in Fig. 2c. Thus, is dendrite fragmentation instead of heterogeneous nucleation is likely the mechanism of grain reefing.

The low melting point particles, $\mathrm{Al}_{8} \mathrm{Mn}_{5}$, could not have caused grain refining. This is because they always form just before the Mg-rich phase (Mg) does (as shown in Fig. 10) regardless the preweld is single- or multiple-pass. In other words, if $\mathrm{Al}_{8} \mathrm{Mn}_{5}$ particles were effective nucleants, the test welds in Figs. 11 and 12 should not have changed their grain size upon entering the prewelds.

Fig. 13 shows the progressive reduction in the grain size in AZ31 Mg welds. Welding over the workpiece without arc oscillation results in coarse columnar grains in AZ $31 \mathrm{Mg}$ as shown in Fig. 13a. The same welding procedure but with transverse arc oscillation at 1 $\mathrm{Hz}$ frequency and $2 \mathrm{~mm}$ amplitude produces fine equiaxed grains as shown in Fig. 13b. Welding with transverse arc oscillation over a wider preweld made in a single pass with no arc oscillation produces much finer equiaxed grains as shown in Fig. 13c. The same welding procedure but with a 6-pass preweld produces even finer equiaxed grains as shown in Fig. 13d.

The grain refining mechanism of AZ91 Mg welds made with transverse arc oscillation can also be identified using the same overlap welding procedure. Due to space limit this will presented elsewhere. 


\subsection{Effect of arc oscillation on dendrite fragmentation}

Fig. 14 shows the cooling curves recorded by a stationary thermocouple at the weld centerline during welding. Without arc oscillation, the temperature falls continuously during cooling as shown in Fig. 14a. With transverse arc oscillation at $1 \mathrm{~Hz}$ frequency and $2 \mathrm{~mm}$ amplitude, however, the weld metal temperature rises periodically during cooling as shown in Fig. 14b. The time interval between two consecutive temperature peaks is about 0.5 second. Since the frequency of arc oscillation is $1 \mathrm{~Hz}$, the thermocouple senses reheating twice per second during cooling, once when the arc swings from one side of the weld to the other and once more when it swings back to complete one arc oscillation cycle.

Reheating can cause remelting of the side arms of the dendrites of a solidifying alloy, so can growth-rate fluctuations induced by unsteady flow of the warm liquid [34-38]. Fig. 15 is an example of side arm remelting caused by growth-rate fluctuations [34]. Remelting occur preferentially at the roots of side arms (i.e., at their junctions with primary stalks) because the roots tend to be necked. This necking phenomenon has been clearly revealed in dendrites of organic alloys by direct observation or in dendrites of metallic alloys by high-brilliance synchrotron X-radiation imaging [35]. The roots become necked because the solute is rejected (equilibrium segregation ratio $k<1$ ) into the liquid around the roots by the side arms as well as the primary stalk and the liquid thus becomes higher in solute concentration locally. This local excess solute rejection at the roots restricts the growth at the roots. This is because the roots need to reject solute in order to grow but the liquid around the roots already has excess solute. Remelting occurs 
preferentially at the necked roots because the melting point is reduced by the smaller radius of curvature at the necked roots [27].

Dendrite fragmentation is often envisioned as dendrites breaking mechanically during solidification by forced convection in the liquid immediately ahead of the dendrites that exerts a bending force on the dendrites. In fact, the word "breakup" is often used to describe dendrite fragmentation, e.g., in studying grain refining in Al welds [22]. However, Pilling and Hellawell [36] pointed out that metallic dendrites do not break mechanically in the course of a casting operation. They may be plastically bent, but bending moments and fluid flow calculations indicate this is highly unlikely. Since the dendrite array in the mushy zone is much shorter and much more densely packed in welding than in casting, dendrite fragmentation caused by mechanical breakdown of dendrites is less likely to occur in welding than in casting.

It has been shown in casting/solidification $[35,37]$ that thermosolutal convection inside the dendrite array can also cause remelting of dendrites. Thermosolutal convection [39] can be induced by the combination of the temperature gradient and the concentration gradient of a heavier or lighter solute inside the mushy zone. The interdendritic space available for thermosolutal convection, which is related to the so-called "permeability", is much smaller in welding than in casting [40-42]. Thus, thermosolutal convection is also more difficult to develop inside the mushy zone in welding than in casting.

In summary, in view of the side-arm remelting of dendrites caused by reheating and growth-rate fluctuations in casting, reheating caused by transverse arc oscillation (Fig. $116 \mathrm{~b})$ is likely to cause dendrite fragmentation by remelting of side arms. 


\subsection{Effect of arc oscillation on constitutional supercooling}

Fig. 14b also shows that with transverse arc oscillation the overall slope of the cooling curve is significantly reduced. Since the constant travel speed of the torch is identical with and without arc oscillation, the time axis $t$ can be converted into the distance axis $x$ along the torch travel direction. The slope $d T / d x$ is the temperature gradient $G$ along the x-direction during welding. For the purpose of comparison, take $G$ at liquidus temperature $T_{L}$. As an approximation, consider the average slope. As shown, $G$ is reduced from $49.9{ }^{\circ} \mathrm{C} / \mathrm{mm}$ without arc oscillation to $29.4{ }^{\circ} \mathrm{C} / \mathrm{mm}$ with arc oscillation. The component of the growth rate along the $\mathrm{x}$-direction is $R=3.18 \mathrm{~mm} / \mathrm{s}$, that is, the torch travel speed. Thus, the $G / R$ ratio along the x-direction is reduced from 15.7 ${ }^{\circ} \mathrm{Cs} / \mathrm{mm}^{2}$ without arc oscillation to $9.3{ }^{\circ} \mathrm{Cs} / \mathrm{mm}^{2}$ with arc oscillation. Since the $G / R$ ratio is reduced significantly, constitutional supercooling is increased significantly by transverse arc oscillation [13]. Thus, the region of undercooled liquid ahead of the growth front is widened.

Since convection is limited to within the weld pool, that is, above the liquidus temperature $T_{L}$, convection enhanced by arc oscillation can be expected to reduce the temperature gradient $G$ in the weld pool. However, below $T_{L}$ the temperature gradient $G$ is also significantly reduced, which cannot be caused by enhanced convection in the weld pool. It will be explained below that transverse arc oscillation can reduce $G$ significantly through preheating.

With transverse arc oscillation, the arc tends to weld over the warm metal just solidified during the previous cycle of arc oscillation, that is, welding is in fact conducted 
with much preheating. This can be illustrated by Fig. 16. When the weld pool travels from Position 6 to Position 7, the adjacent metal covered by the pool previously at Positions at 4 and 5 is still very warm. Thus, welding from Position 6 to 7 is in fact done with high preheating. It is well known in welding that preheating the workpiece significantly reduces the cooling rate during welding. The use of preheating to reduce the cooling rate and hence Martensite formation and hydrogen cracking is standard practice in welding high strength steel [13]. With Rosenthal's analytical equation for 2-D welding heat flow, it can be shown that the cooling rate and the temperature gradient $G$ are both proportional to $\left(T-T_{o}\right)^{3}$, that is, reduced significantly by raising the preheat temperature $T_{o}$. Thus preheating caused by transverse arc oscillation can be expected to reduce the cooling rate and the temperature gradient $G$ though the workpiece is not preheated as a whole to a low level of temperature but locally to a very high temperature near the melting point.

Since the temperature gradient $G$ is reduced by transverse arc oscillation (Fig. 14b), according to the constitutional supercooling theory $[13,27]$, the extent of constitutional supercooling in the liquid ahead of the growth front can also be expected to be reduced. However, the growth front here is not planar but dendritic. So, the classic constitutional supercooling theory $[13,27]$ is difficult to apply. It has been shown that the solute rejected by the tip of a growing columnar dendrite can cause constitutional supercooling in the liquid ahead of the tip $[43,44]$. When the constitutional supercooling exceeds the undercooling required for nucleation, new equiaxed grains can nucleate upon heterogeneous nuclei ahead of the tip. If such new equiaxed grains grow significantly, 
they can block off the columnar grain and cause the columnar-to-equiaxed transition to occur.

Fig. 17 is a schematic sketch explaining how transverse arc oscillation helps grain refining. It shows that transverse arc oscillation can cause reheating and hence dendrite fragmentation by melting off dendrite arms. It also shows that the temperature gradient $G$ is reduced by transverse arc oscillation, which increases constitutional supercooling to help the dendrite fragments survive and grow into equiaxed grains. This model is consistent with the following things: 1 . identification of dendrite fragmentation as the grain refining mechanism caused by transverse arc oscillation (Figs. 2, 11 and 12), 2. reheating during cooling and reduction in the temperature gradient $G$ (Fig. 14b), and 3 . side-arm remelting induced by reheating or growth-rate fluctuations in casting (Fig. 15). However, it should be emphasized that the model is speculative, lacks quantitative calculations, and needs further verification. No theoretical calculations were conducted in the present study to predict the columnar-to-equiaxed transition of grains in the welds made with arc oscillation as attempted in some other studies [10, 11]. It was not attempted in the present study because of the unknown values of many parameters that are needed for computation. For instance, the amount of undercooling needed for nucleation of new grains and the number of nucleation sites are unknown $[10,11]$. Although equations or models based on 1-D solidification without fluid flow [43, 45] were used to predict the columnar-to-equiaxed transition of grains in welding $[10,11]$, heat transfer, fluid flow and solidification in arc welding is clearly 3-D [46, 47]. Furthermore, the oscillating arc and the weld pool should be coupled in computer 
simulation since the arc is dynamic and no longer axisymmetric as a stationary arc in welding without arc oscillation.

\section{Conclusions}

Welding of AZ31 Mg and AZ91 Mg alloys was conducted by gas-tungsten arc welding with and without transverse arc oscillation. The workpiece was $1.6 \mathrm{~mm}$ thick and the arc length was $2 \mathrm{~mm}$. The conclusions are as follows:

1. Significant grain refining can be produced in welds of AZ31 Mg and AZ91 Mg by transverse arc oscillation.

2. Within the frequency range ( 1 to $50 \mathrm{~Hz})$ and the amplitude range (0 to one arc length) of the arc oscillator used in the present study, the optimum condition appears to be $1 \mathrm{~Hz}$ and $2 \mathrm{~mm}$ (at the $2 \mathrm{~mm}$ arc length used) for both alloys.

3. Under the optimum condition of arc oscillation, grain refining does not appear very sensitive to the torch travel speed, at least not in the speed ranges investigated.

4. Without arc oscillation, coarse columnar grains exist throughout AZ31 Mg welds but thin columnar grains and even equiaxed grains can exist in AZ91 Mg welds. At high frequencies (e.g., 13 to $50 \mathrm{~Hz}$ at $2 \mathrm{~mm}$ amplitude) columnar grains can reappear in AZ31 Mg welds but not AZ91 welds.

5. AZ91 Mg has a much greater tendency to form equiaxed grains than $\mathrm{AZ31} \mathrm{Mg}$ because constitutional supercooling tends to be more significant in AZ91 Mg due to its much higher $\mathrm{Al}$ content. 
6. With the help of the overlap welding procedure developed originally for Al welds, the grain refining mechanism in $\mathrm{AZ31} \mathrm{Mg}$ welds made with transverse arc oscillation has been identified as dendrite fragmentation.

7. Cooling curves recorded during welding of AZ31 Mg show that transverse arc oscillation can cause reheating during weld pool solidification, which as shown in casting/solidification can help dendrite fragmentation by melting off dendrite side arms.

8. The cooling curves also show that transverse arc oscillation can reduce the temperature gradient $G$ during weld pool solidification and thus increase constitutional supercooling to help dendrite fragments survive and grow into fine equiaxed grains.

\section{Acknowledgements}

The authors gratefully acknowledge the support of the National Science Foundation of the United States under Grant No. DMR 1500367 and the University of Wisconsin Foundation. The financial support by the China Scholarship Council for Tao Yuan to work as a visiting graduate student at UW-Madison is also acknowledged.

\section{References}

[1] S. Kou and Y. Le, Grain structure and solidification cracking in oscillated arc welds of 5052 aluminum alloy, Metal. Trans. A, 1985, 16, 1345-1352

[2] S. Kou and Y. Le, Alternating grain orientation and weld solidification cracking, Metal. Trans. A, 1985, 16, 1887-1896. 
[3] S. Kou and Y. Le, Improving weld quality by low-frequency arc oscillation, Weld. J., $1986,65,305 \mathrm{~s}-313 \mathrm{~s}$

[4] G. Madhusudhan Reddy, Amol A. Gokhale, K. Prasad Rao, Weld microstructure refinement in a 1441 grade aluminium-lithium alloy, J. Mater. Sci., 1997, 32, 4117-126.

[5] G.D. Janaki Ram, R. Murugesan and S. Sundaresan, Fusion zone grain refinement in aluminum alloy welds through magnetic arc oscillation and its effect on tensile behavior, J. Mater. Engineer. Perform., 1999, 8, 513-520.

[6] S.R. Koteswara Rao, G. Madhusudhana Reddy, M. Kamaraj, K. Prasad Rao, Grain refinement through arc manipulation techniques in Al-Cu alloy GTA welds, Mater. Sci. Engineer. A, 2005, 404, 227-234.

[7] N.S. Biradar and R. Raman, Grain refinement in Al-Mg-Si alloy TIG welds using transverse mechanical arc oscillation, J. Mater. Engineer. Performance, 2012, 21, 2495-2502.

[8] M. G. Mousavi, M. J. M. Hermans, I. M. Richardson, and G. Den Ouden, Grain refinement due to grain detachment in electromagnetically stirred AA7020 welds. Sci. Technol. Weld. Join., 2003, 8, (4), 309-312.

[9] S. Mahajan, N. S. Biradar, R. Raman, S. Mishra, Effect of mechanical arc oscillation on the grain structure of mild steel weld metal, Trans. Indian Ins. Met., $2012,65,171-177$. 
[10] Y. C. Lim, X. Yu, J. H. Cho, J. Sosa, D. F. Farson, S. S. Babu and S. McCracken, Effect of magnetic stirring on grain structure refinement. Part 1 - Autogenous nickel alloy welds, Sci. Technol. Weld. Join., 2010, 15, (7), 583-589.

[11] Y. C. Lim, X. Yu, J. H. Cho, J. Sosa, D. F. Farson, S. S. Babu, S. McCracken and B. Flesner, Effect of magnetic stirring on grain structure refinement Part 2 - Nickel alloy weld overlays, Sci. Technol. Weld. Join., 2010, 15, (5), 400-406.

[12] S. Kou and Y. Le, Nucleation Mechanisms and Grain Refining of Weld Metal, Weld. J., 1986, 65, 305s-313s.

[13] S. Kou, Welding Metallurgy, 2d edition, John Wiley and Sons, Hoboken, NJ, 2003.

[14] H. Watarai, Trend of research and development for magnesium alloys - Reducing the weight of structural materials in motor vehicles, Quarterly Review, 2006, 18, 84-97.

[15] "Magnesium Vision 2020: A North American automotive strategic vision for magnesium", USAMP, United States Automotive Materials Partnership - a consortium of the United States Council for Automotive Research, MG 2020, released 11, 1, 2006, pp. 1-34.

[16] M. K. Kulekci, Magnesium and its alloys applications in automotive industry, International Journal of Advanced Manufacturing Technology, 2008, 39, 851-865.

[17] D. C. Wagner, Y. K. Yang and S. Kou, Spatter and Porosity in Gas-Metal Arc Welding of Magnesium Alloys: Mechanisms and Elimination, Weld. J., 2013, 92, p.347-s. 
[18] X. Chai, Y. K. Yang, S. Kou, Oxide Films, High Crowns and Fingers in Gas-Metal Arc Welds of Mg Alloys, Mechanisms of Formation and Mitigation, Weld. J., 2015, $94,16 s-33 s$.

[19] T. Yuan, X. Chai, Z. Luo, and S. Kou, Predicting susceptibility of magnesium alloys to weld-edge cracking, Acta Materialia, 2015, 90, 242-251.

[20] N. K. Babu and C. E. Cross, Grain refinement of AZ31 magnesium alloy weldments by AC pulsing technique, Metall. Mater. Trans. A 43A (2012) 4145-4154.

[21] T. Yuan, S. Kou and Z. Luo, Grain Refining by Ultrasonic Stirring of the Weld Pool, Acta Materialia 106 (2016) 144-154.

[22] G. D. Janaki Ram, R. Murugesan, S. Sundaresan, Fusion zone grain refinement in aluminum alloy welds through magnetic arc oscillation and its effect on tensile behavior, Journal of Materials Engineering and Performance, 8 (1999) 513-520.

[23] B. P. Pearce, H. W. Kerr, Grain structures in magnetically stirred GTA welds of aluminum alloys, Metall. Trans. B, 1981, 12B, 479-486.

[24] X. Wang, J. Song, W. Vian, H. Ma and Q. Han, The interface of $\mathrm{TiB}_{2}$ and $\mathrm{Al}_{3} \mathrm{Ti}$ in molten aluminum, Metallurgical and Materials Transactions B, published online, December 2015.

[25] P. Schempp, C. E. Cross, A. Pittner, G. Oder, R. S. Neumann, H. Rooch, I. Dörfel, W. Österle, and M. Rethmeier, Solidification of GTA aluminum weld metal: Part I Grain morphology dependent upon alloy composition and grain refiner content, Welding Journal, vol. 93, 2014, 53-s to 59-s. 
[26] A. Maltais, D. Dube, F. Roy and M. Fieset, Optical anisotropy of a color-etched AZ91 magnesium alloy, Materials Characterization, 54 (2005) 315-326.

[27] M. C. Flemings, Solidification Processing, McGraw-Hill, New York, NY, 1974.

[28] A. Stevenson: Metals Handbook, ASM International, Materials Park, OH, 1989, vol. 4, p.899.

[29] D. H. StJohn, P. Cao, M. Qian, M. A. Easton, A new analytical approach to reveal the mechanisms of grain refinement, Adv. Eng. Mater. 6 (2007) 739-746.

[30] Pandat, Phase Diagram Calculation Software Package for Multicomponent Systems, Computherm LLC, Madison, WI, 2013.

[31] PanMagnesium, Thermodynamic Database for Magnesium Alloys, Computherm LLC, Madison, WI, 2013.

[32] X. Chai, T. Yuan and S. Kou: "Liquation and Liquation Cracking in Partially Melted Zones of Magnesium Welds", Welding Journal, vol. 95, 2016, pp. 57s to $67 \mathrm{~s}$.

[33] L. Wang, Q. Qiao, Y. Liu, X. Song, Formability of AZ31 Mg alloy sheets within medium temperatures, Journal of Magnesium and Alloys, 2013, 1: 312-317.

[34] K. A. Jackson, J. D. Hunt, D. R. Uhlmann, T. P. Seward, On origin of equiaxed zone in castings, Trans. Met. Soc. AIME, 236 (1966) 149.

[35] D. Ruvalcaba, R. H. Mathiesen, D. G. Eskin, L. Arnberg, L. Katgerman, In situ observations of dendritic fragmentation due to local solute-enrichment during directional solidification of an aluminum alloy, Acta Mater., 55 (2007) 4287-4292. 
[36] J. Pilling, A. Hellawell, Mechanical deformation of dendrites by fluid flow, Metall. Mater. Trans. A, 27 (1996) 229-232.

[37] A. Hellawell, S. Liu and S. Z. Lu, Dendrite fragmentation and the effect of fluid flow in castings, J. Miner. Met. Mater., 49 (1997) 18-20.

[38] R. H. Mathiesen, L. Anberg, P. Bleuet, A. Somogyi, Crystal fragmentation and columnar-to-equiaxed transitions in $\mathrm{Al}-\mathrm{Cu}$ studied by synchrotron $\mathrm{X}$-ray video microscopy, Metall. Mater. Trans. A, 37 (2006) 2515-2524.

[39] S. Kou, Transport Phenomena and Materials Processing, John Wiley and Sons, Hoboken, NJ, 1996.

[40] S. D. Ridder, S. Kou, R. Mehrabian, Effect of fluid flow on macrosegregation in axisymmetric ingots. Metall. Trans. B, 12B (1981), pp. 435-447.

[41] S. Kou, D. R. Poirier, M. Flemings, Macrosegregation in Rotated Remelted Ingots, Metallurgical Transactions B, vol. 9B, 1978, pp. 711-719.

[42] S. Kou, D. R. Poirier and M. C. Flemings, Macrosegregation in Electroslag Remelted Ingots, Electric Furnace Proceedings, 1977, vol. 35, p. 221.

[43] M. Gaumann, R. Trivedi and W. Kurz, Nucleation ahead of the advancing interface in directional solidification', Mater. Sci. Eng. A, A226 (1997) 763-769.

[44] S. McFadden, D.J. Browne, A generalized version of an Ivantsov-based dendrite growth model incorporating a facility for solute, measurement ahead of the tip, Computational Materials Science, vol.55, pages 245-254, 2012.

[45] J. D. Hunt, Steady state columnar and equiaxed growth of dendrites and eutectic, Mater. Sci. Eng., 65 (1984) 75-83. 
[46] S. Kou and D. K. Sun, Fluid Flow and Weld Penetration in Stationary Arc Welds, Metallurgical Transactions A, vol. 16A, 1985, p. 203.

[47] S. Kou and Y. H. Wang, Computer Simulation of Convection in Moving Arc Weld Pools, Metallurgical Transactions A, vol. 17A, 1986, p. 2271. 
Table 1 Compositions of AZ31 Mg and AZ61 Mg in wt \%

\begin{tabular}{|l|l|l|l|l|l|l|l|l|l|l|}
\hline & $\mathrm{Al}$ & $\mathrm{Zn}$ & $\mathrm{Mn}$ & $\mathrm{Ca}$ & $\mathrm{Cu}$ & $\mathrm{Fe}$ & $\mathrm{Ni}$ & $\mathrm{Si}$ & Others & $\mathrm{Mg}$ \\
\hline $\begin{array}{l}\mathrm{AZ31} \\
\mathrm{Mg}\end{array}$ & 3.0 & 1.0 & 0.6 & $\begin{array}{l}< \\
0.04\end{array}$ & $\begin{array}{l}< \\
0.05\end{array}$ & $\begin{array}{l}< \\
0.005\end{array}$ & $\begin{array}{l}< \\
0.005\end{array}$ & $\begin{array}{l}< \\
0.05\end{array}$ & $<0.30$ & balance \\
\hline $\begin{array}{l}\text { AZ91 } \\
\mathrm{Mg}\end{array}$ & 8.5 & 0.71 & 0.29 & - & 0.001 & $\begin{array}{l}< \\
0.002\end{array}$ & 0.001 & $<$ & $<0.01$ & balance \\
\hline
\end{tabular}

Table $2 \mathrm{Mg}$ Welds made under various amplitude and frequency of arc oscillation

\begin{tabular}{cccccc}
\hline Alloy & Weld \# & $\begin{array}{c}\text { Current } \\
(\mathrm{A})\end{array}$ & $\begin{array}{c}\text { Welding speed } \\
(\mathrm{mm} / \mathrm{s})\end{array}$ & $\begin{array}{c}\text { Frequency } \\
(\mathrm{Hz})\end{array}$ & $\begin{array}{c}\text { Amplitude } \\
(\mathrm{mm})\end{array}$ \\
& 1 & 75 & $3.18(7.5 \mathrm{ipm})$ & No Oscillation \\
& 2 & 75 & $3.18(7.5 \mathrm{ipm})$ & 1 & 1.0 \\
& 3 & 75 & $3.18(7.5 \mathrm{ipm})$ & 1 & 1.5 \\
$\mathrm{AZ31}$ & 4 & 75 & $3.18(7.5 \mathrm{ipm})$ & 1 & 2.0 \\
$\mathrm{Mg}$ & 5 & 75 & $3.18(7.5 \mathrm{ipm})$ & 13 & 2.0 \\
& 6 & 75 & $3.18(7.5 \mathrm{ipm})$ & 25 & 2.0 \\
& 7 & 75 & $3.18(7.5 \mathrm{ipm})$ & 50 & 2.0 \\
& 8 & 75 & $2.12(5 \mathrm{ipm})$ & 1 & 2.0 \\
& 9 & 75 & $4.23(10 \mathrm{ipm})$ & 1 & 2.0 \\
\hline \multirow{3}{*}{ AZ91 } & 10 & 85 & $2.75(6.5 \mathrm{ipm})$ & No Oscillation \\
$\mathrm{Mg}$ & 11 & 85 & $2.75(6.5 \mathrm{ipm})$ & 1 & 1.0 \\
& 12 & 85 & $2.75(6.5 \mathrm{ipm})$ & 1 & 1.5 \\
& 13 & 85 & $2.75(6.5 \mathrm{ipm})$ & 1 & 2.0 \\
& 15 & 85 & $2.75(6.5 \mathrm{ipm})$ & 13 & 2.0 \\
& 16 & 85 & $2.75(6.5 \mathrm{ipm})$ & 50 & 2.0 \\
\hline
\end{tabular}

Table 3 Experimental conditions for identifying the grain refining mechanism

\begin{tabular}{|c|c|c|c|c|c|c|}
\hline Alloy & Weld Type & $\begin{array}{c}\text { Weld } \\
\#\end{array}$ & $\begin{array}{l}\text { Current } \\
\text { (A) }\end{array}$ & $\begin{array}{l}\text { Welding speed } \\
\qquad(\mathrm{mm} / \mathrm{s})\end{array}$ & $\begin{array}{l}\text { Frequency } \\
\qquad(\mathrm{Hz})\end{array}$ & $\begin{array}{l}\text { Amplitude } \\
\text { (mm) }\end{array}$ \\
\hline & Preweld: 1 pass & 18 & 100 & 3.18(7.5ipm) & \multicolumn{2}{|c|}{ No Oscillation } \\
\hline AZ31 & Test weld & 19 & 75 & 3.18(7.5ipm) & 1 & 2.0 \\
\hline \multirow[t]{2}{*}{$\mathrm{Mg}$} & Preweld: 6 passes & 20 & 100 & $3.18(7.5 \mathrm{ipm})$ & \multicolumn{2}{|c|}{ No Oscillation } \\
\hline & Test weld & 21 & 75 & 3.18(7.5ipm) & 1 & 2.0 \\
\hline
\end{tabular}




\section{Figure Captions}

Fig. 1 Three possible mechanisms of grain refining in welds based on microstructure around aluminum-alloy weld pool preserved by quenching with ice water during welding [12].

Fig. 2 Identification of the nucleation mechanism of equiaxed grains in a weld (i.e., test weld) by overlap welding: (a) grain detachment; (b) dendrite fragmentation or heterogeneous nucleation; (c) heterogeneous nucleation; (d) dendrite fragmentation [12].

Fig. 3 Top view of an AZ31 Mg weld made with transverse arc oscillation at $1 \mathrm{~Hz}$ frequency and $2 \mathrm{~mm}$ amplitude.

Fig. 4 Effect of oscillation amplitude on AZ31 Mg welds (Welding direction: downward): (a) $0 \mathrm{~mm}$ (no oscillation); (b) $1 \mathrm{~mm}$; (c) $1.5 \mathrm{~mm}$; (d) $2 \mathrm{~mm}$. Oscillation frequency is $1 \mathrm{~Hz}$. Torch travel speed: $3.18 \mathrm{~mm} / \mathrm{s}$.

Fig. 5 Effect of oscillation frequency on AZ31 Mg welds: (a) $1 \mathrm{~Hz}$; (b) $13 \mathrm{~Hz}$; (c) 25 Hz; (d) $50 \mathrm{~Hz}$. Amplitude: $2 \mathrm{~mm}$. Torch travel speed: $3.18 \mathrm{~mm} / \mathrm{s}$.

Fig. 6 Effect of travel speed on AZ31 Mg welds: (a) $2.12 \mathrm{~mm} / \mathrm{s}$; (b) $3.18 \mathrm{~mm} / \mathrm{s}$; (c) $4.23 \mathrm{~mm} / \mathrm{s}$. Amplitude: $2 \mathrm{~mm}$. Frequency: $1 \mathrm{~Hz}$.

Fig. 7 Effect of the oscillation amplitude on AZ91 Mg welds: (a) no oscillation; (b) 1 mm; (c) $1.5 \mathrm{~mm}$; (d) $2 \mathrm{~mm}$. Oscillation frequency: $1 \mathrm{~Hz}$. Torch travel speed: 2.75 $\mathrm{mm} / \mathrm{s}$. Welding direction is downward. Dark arrowheads indicate boundaries between base metals and fusion zones, i.e., external fusion boundaries.

Fig. 8 Effect of the oscillation frequency on AZ91 Mg welds (Welding direction: 
downward): (a) $1 \mathrm{~Hz}, 2 \mathrm{~mm}$; (b) $13 \mathrm{~Hz}$; (c) $50 \mathrm{~Hz}$. Amplitude: $2 \mathrm{~mm}$; torch travel speed: $2.75 \mathrm{~mm} / \mathrm{s}$.

Fig. 9 Effect of travel speed on AZ91 Mg welds: (a) no oscillation; (b) $2.75 \mathrm{~mm} / \mathrm{s}$; (c) $4.23 \mathrm{~mm} / \mathrm{s}$; (d) $6.35 \mathrm{~mm} / \mathrm{s}$. Amplitude: $2 \mathrm{~mm}$. Frequency: $1 \mathrm{~Hz}$.

Fig. 10 Curve of temperature vs. fraction solid showing formation of intermetallic compounds during solidification of AZ31 Mg, calculated using Pandat [30] and PanMagnesium [31] of CompuTherm.

Fig. 11 Overlap between AZ31 Mg test Weld \#19 and preweld \#18 suggesting either dendrite fragmentation or heterogeneous nucleation as grain refining mechanism: (a) no overlap; (b) overlap. Broken white curve hereinafter indicates internal fusion boundary.

Fig. 12 Overlap between AZ31 Mg test weld \#21 and preweld \#20 suggesting dendrite fragmentation as grain refining mechanism: (a) no overlap; (b) overlap.

Fig. 13 Progressive grain size reduction in welding AZ31 Mg: (a) no oscillation; (b) arc oscillation (at $1 \mathrm{~Hz}$ frequency and $2 \mathrm{~mm}$ amplitude); (c) arc oscillation over 1-pass preweld; (d) arc oscillation over 6-pass preweld.

Fig. 14 Effect of arc oscillation on cooling curve during welding of AZ31 Mg: (a) without arc oscillation; (b) with transverse arc oscillation to cause reheating (temperature rise) and increase constitutional supercooling (by reducing G/R).

Fig. 15 Reheating or growth rate fluctuations can cause dendrite arms to melt off and form dendrite fragments, which occurs preferentially at the necked roots where the arms are connected to the primary stalks. Photo shows melting of dendrite 
arms of carbon tetrabromide alloyed with salol caused by growth rate fluctuations, slower before AA', faster between $\mathrm{AA}^{\prime}$ and BB', and slower again after BB' [34].

Fig. 16 Weld pool zigzaging as welding electrode advances from left to right along a straight line at speed $\mathrm{u}$.

Fig. 17 Arc oscillation helping grain refining: (a) no arc oscillation; (b) arc oscillation promoting dendrite fragmentation through reheating and constitutional supercooling through reducing temperature gradient $G$ (Fig. 14b) to help dendrite fragments survive and grow into equiaxed grains. 


\section{base metal (S)}

\section{Welding direction}

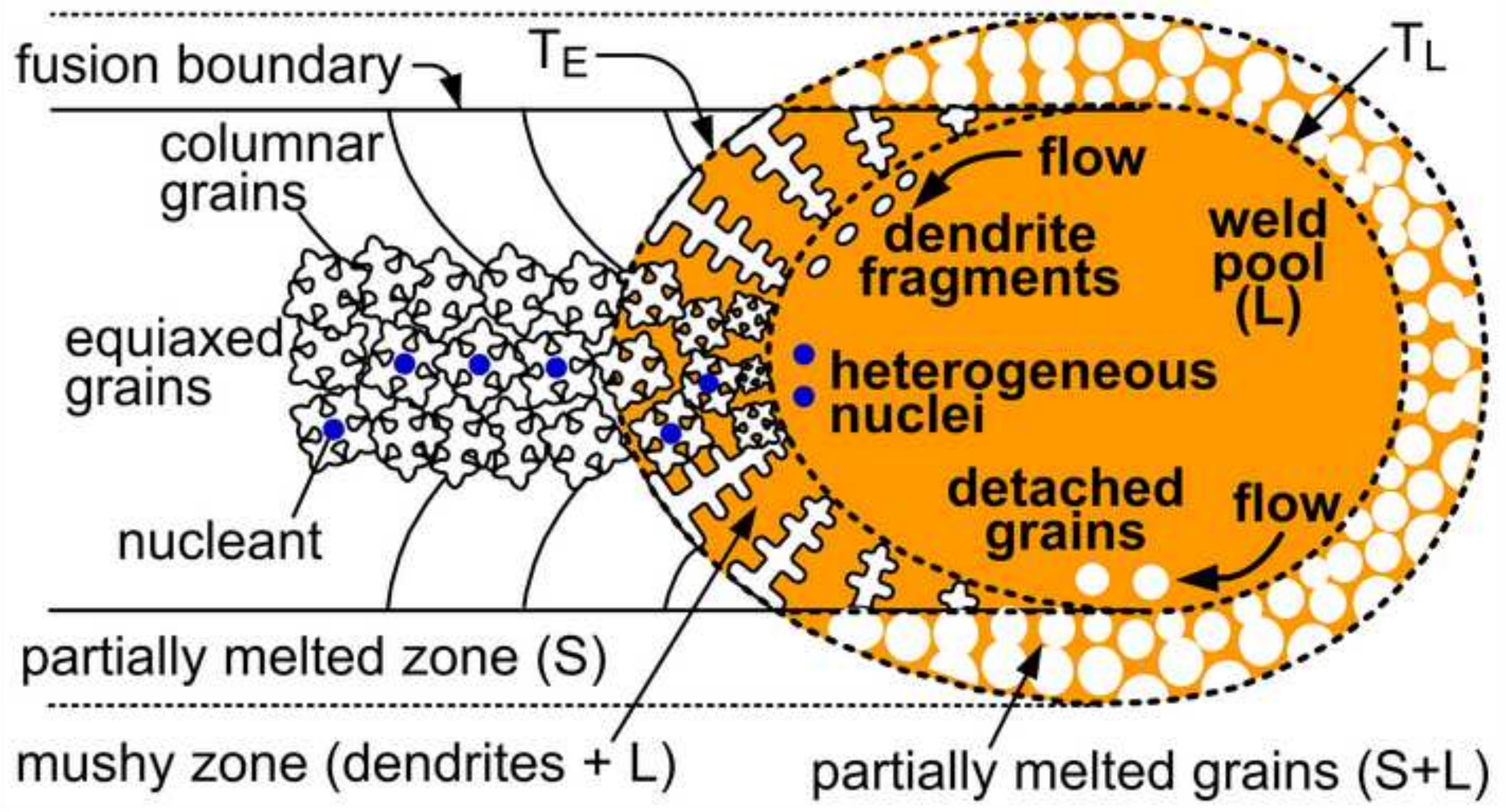




\section{Identifying nucleation mechanism by overlap welding}

Test weld: arc oscillation, single-pass

Preweld: no oscillation, single- or multi-pass

\section{Grain Detechament:}

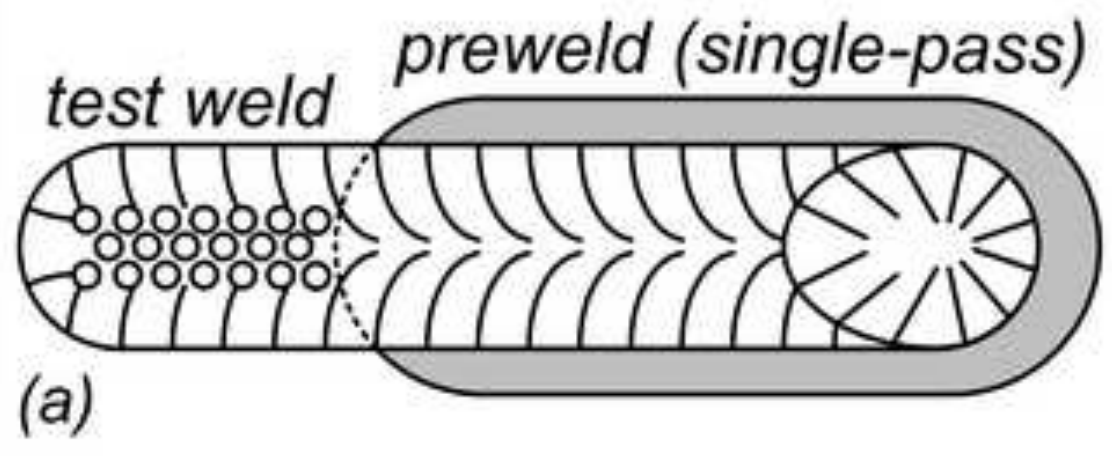

Heterogeneous Nucleation or Dendrite Fragmentation:

(c) Heterogeneous Nucleation: preweld (multi-pass to dissolve nuclei)

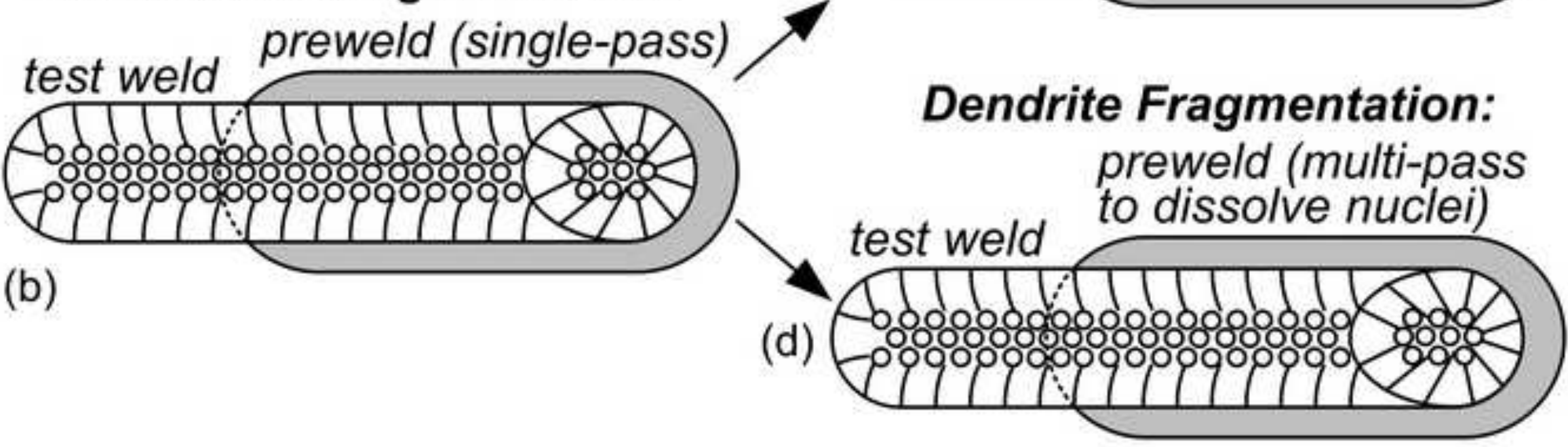




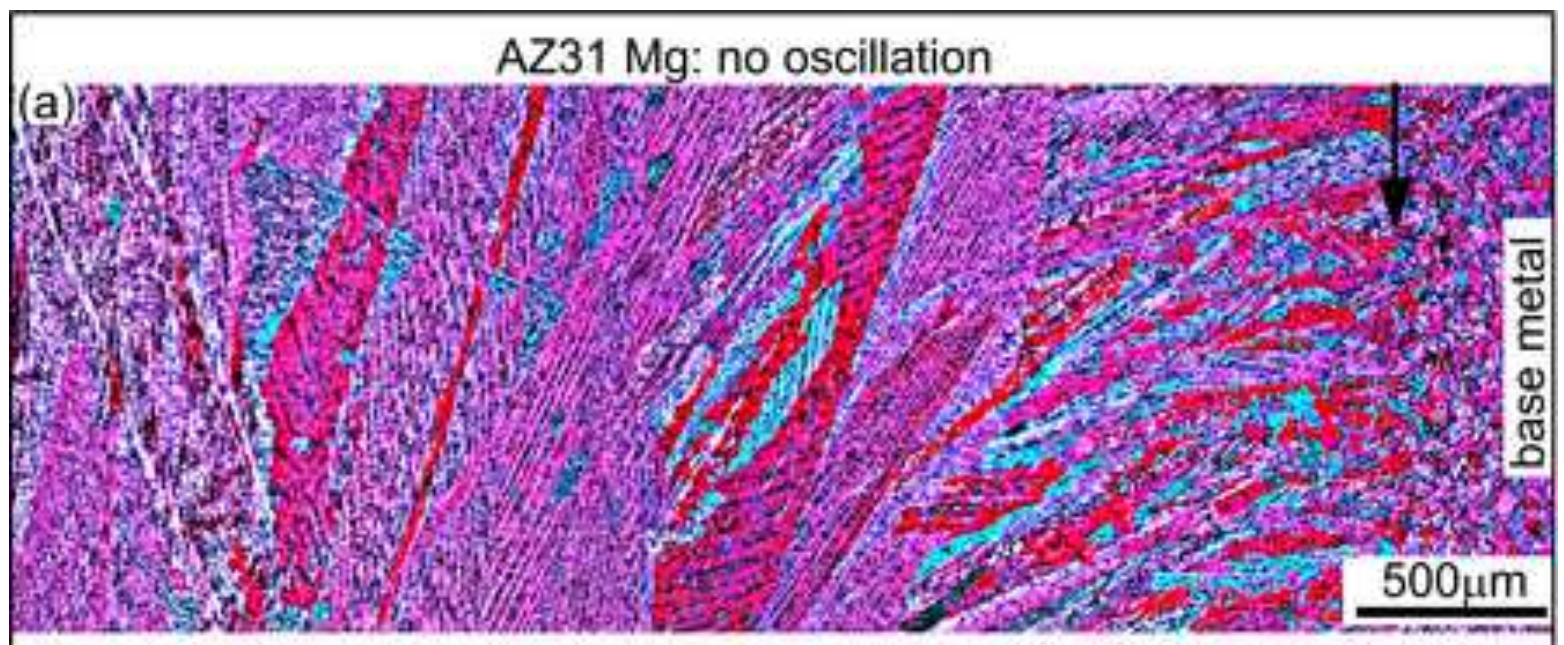

AZ31 Mg: $1 \mathrm{~mm}$ amplitude

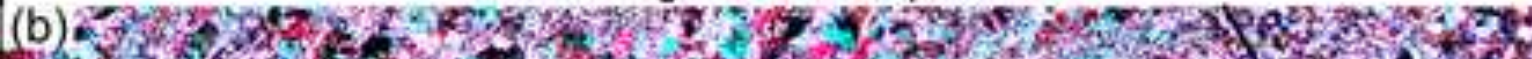

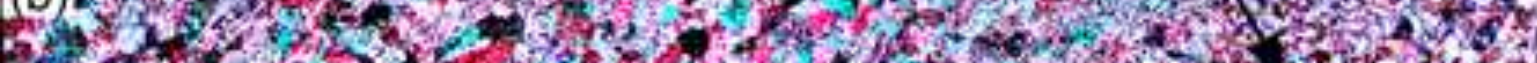

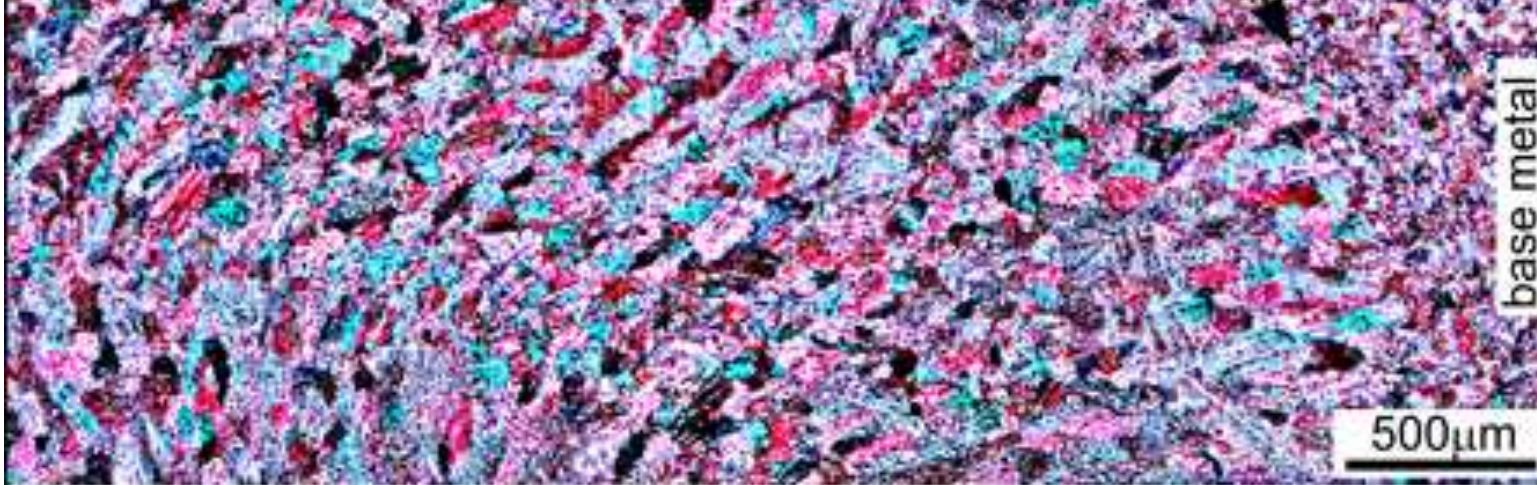

AZ31 Mg: $1.5 \mathrm{~mm}$ amplitude

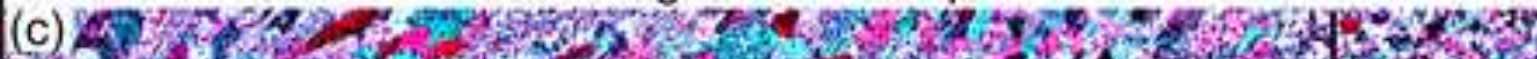

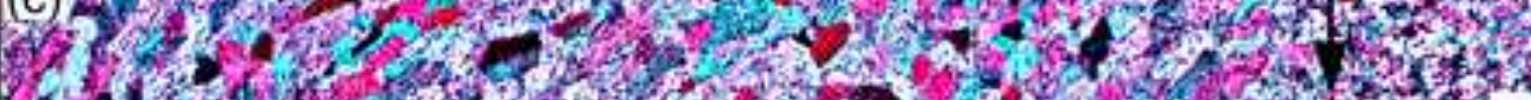

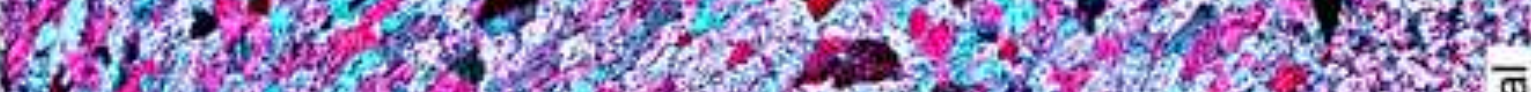

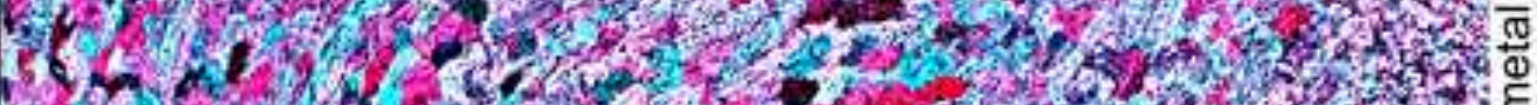

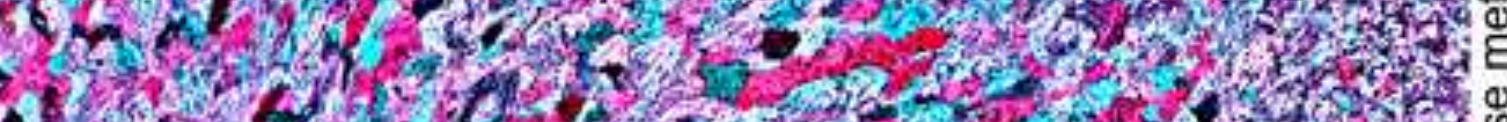

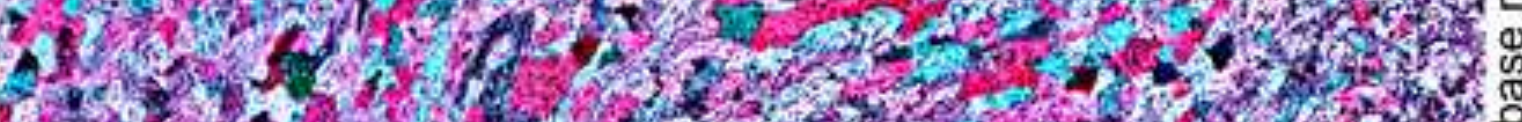

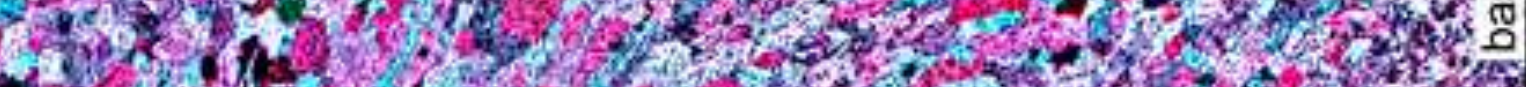

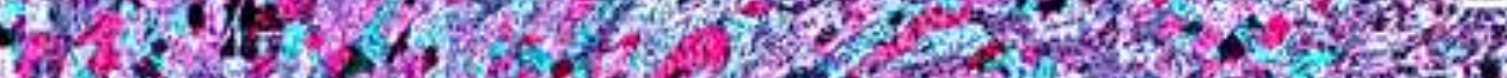

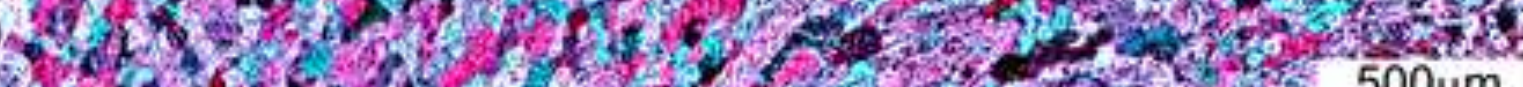

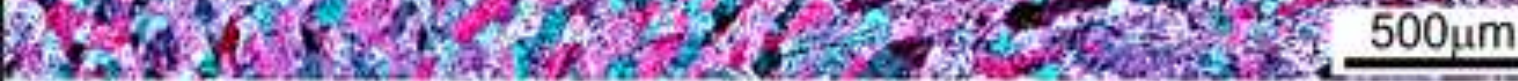

AZ31 Mg: $2 \mathrm{~mm}$ amplitude

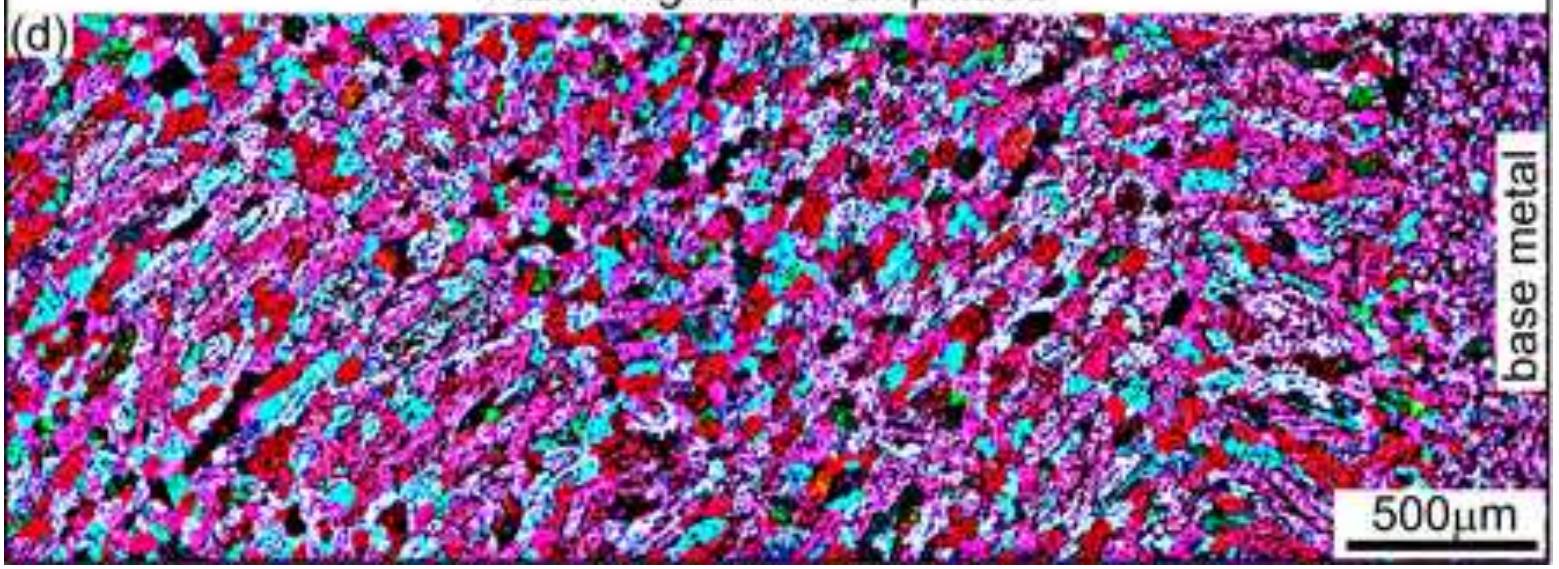




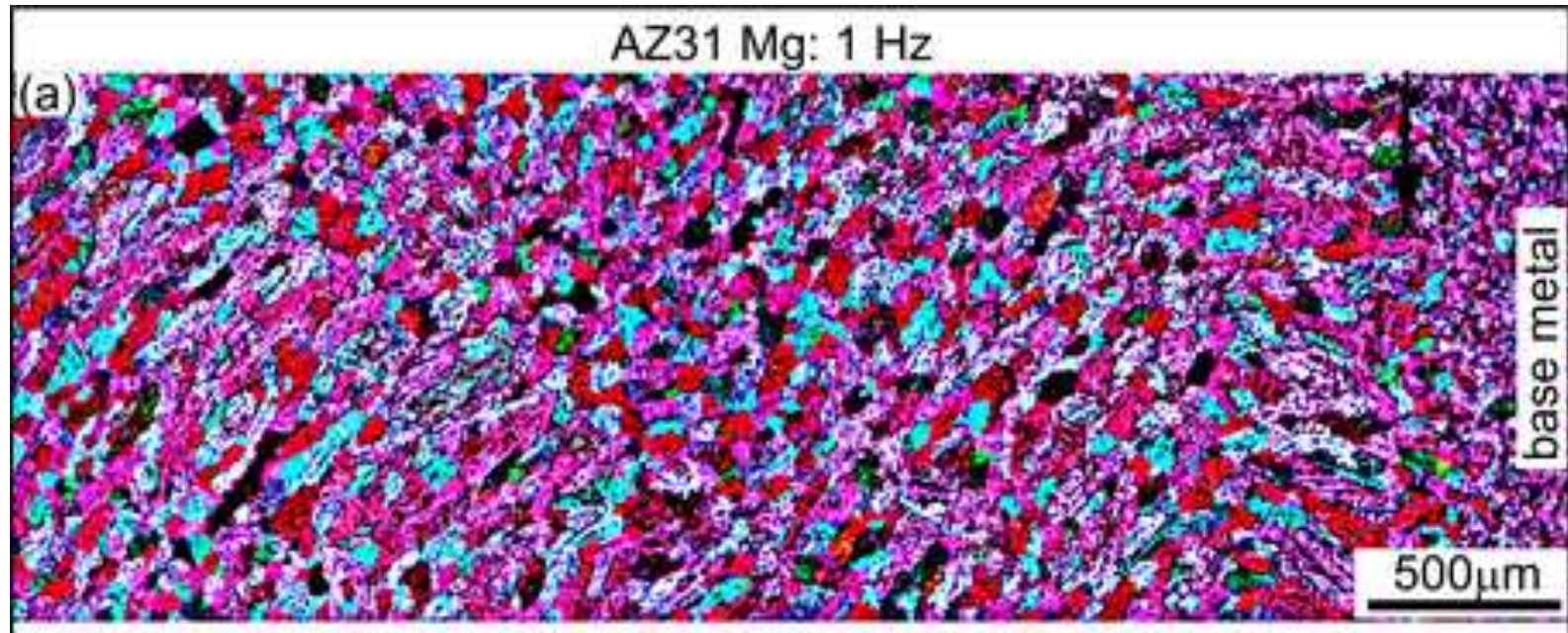

AZ31 Mg: $13 \mathrm{~Hz}$

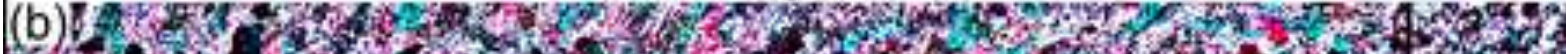

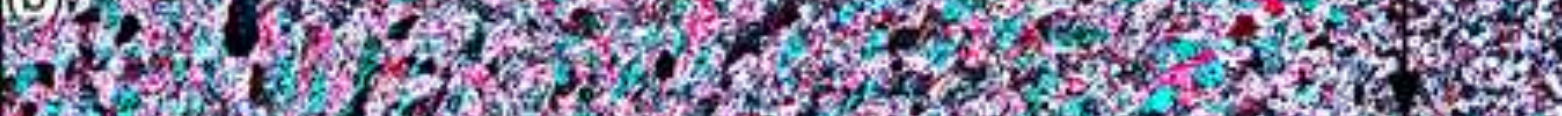

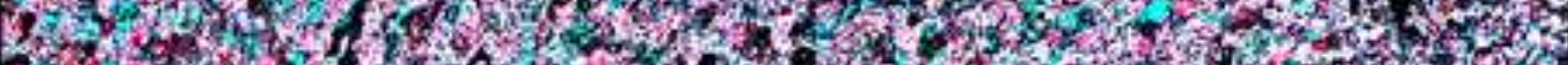

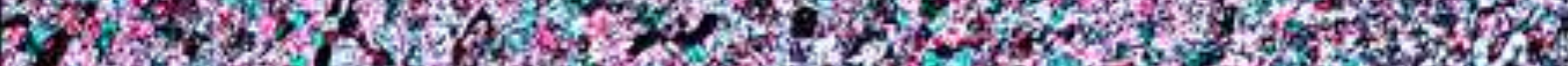

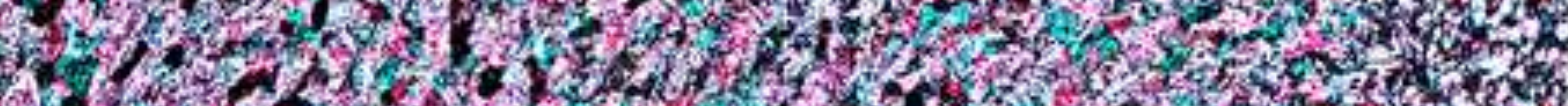

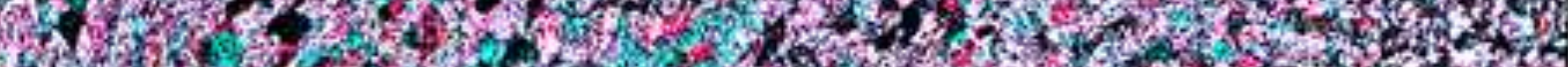

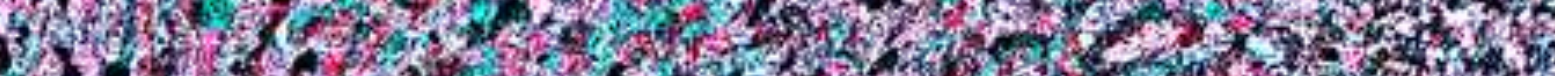

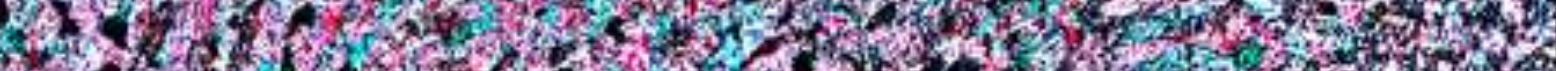

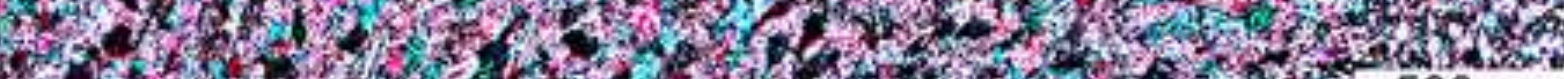

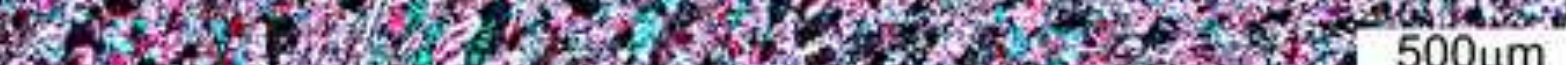

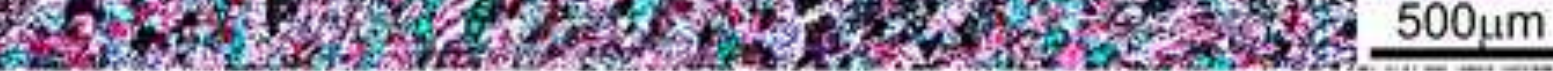

AZ31 Mg: $25 \mathrm{~Hz}$

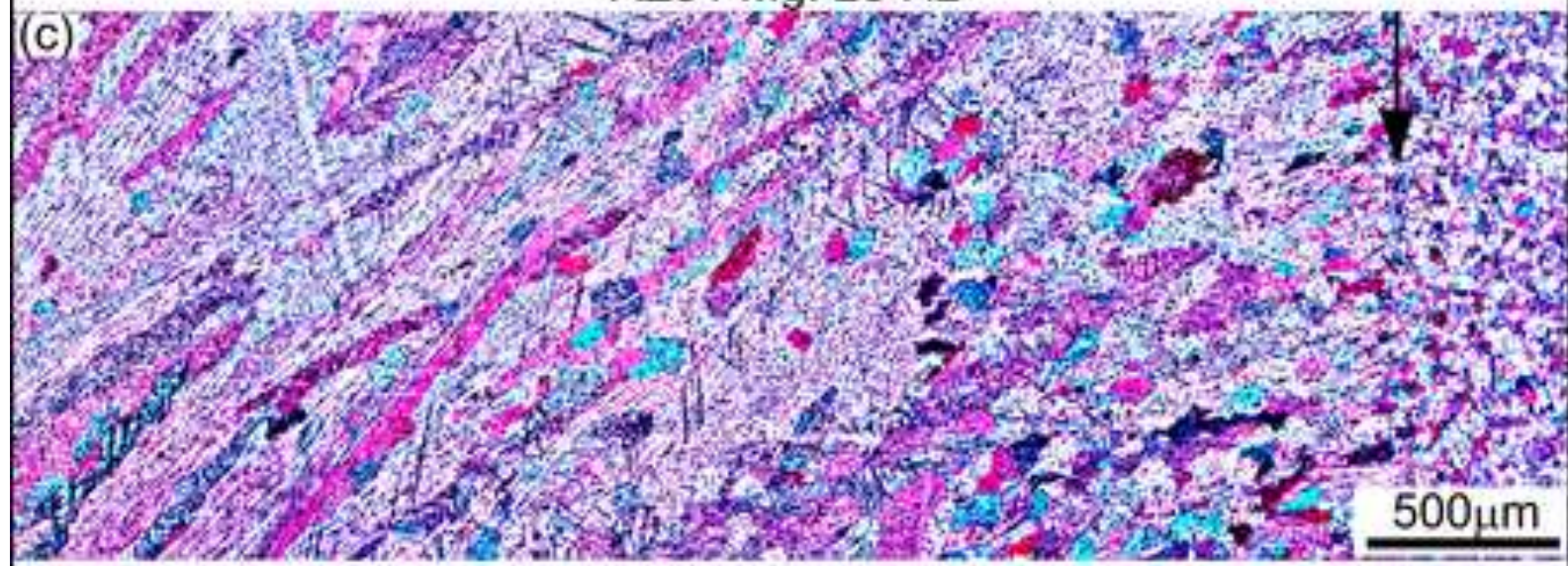

AZ31 Mg: $50 \mathrm{~Hz}$

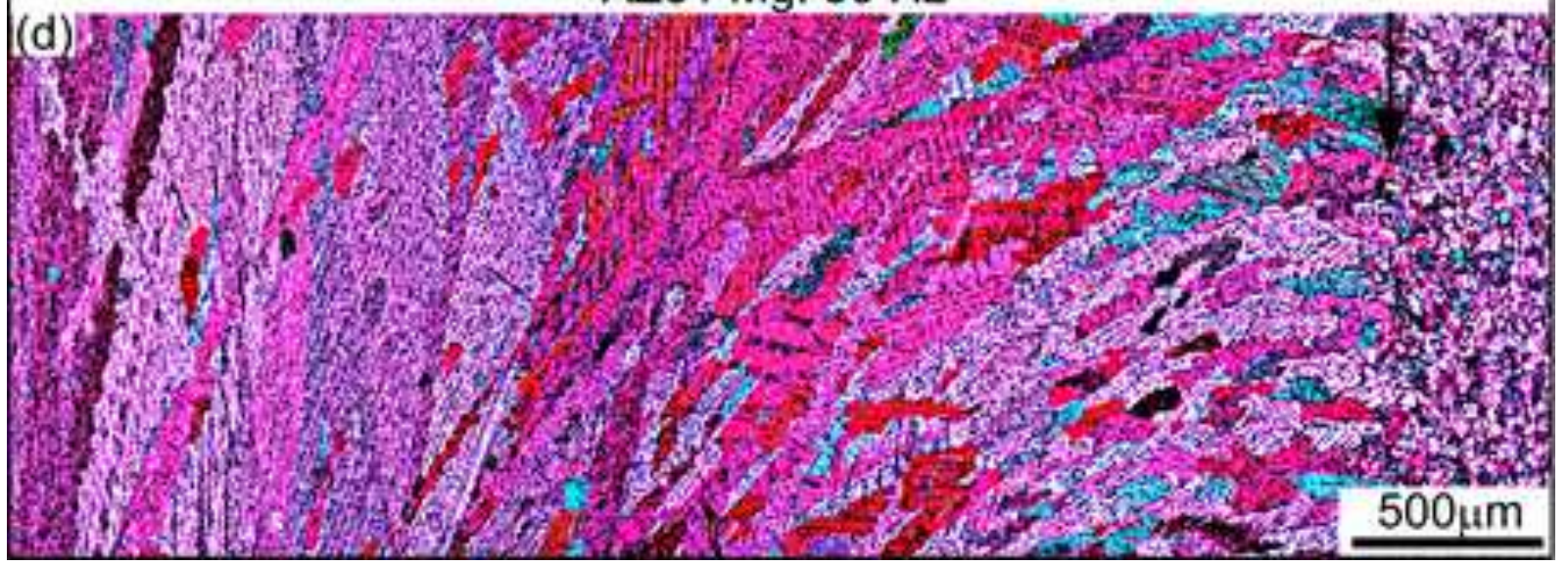




\section{AZ31 Mg: $2.12 \mathrm{~mm} / \mathrm{s}$}

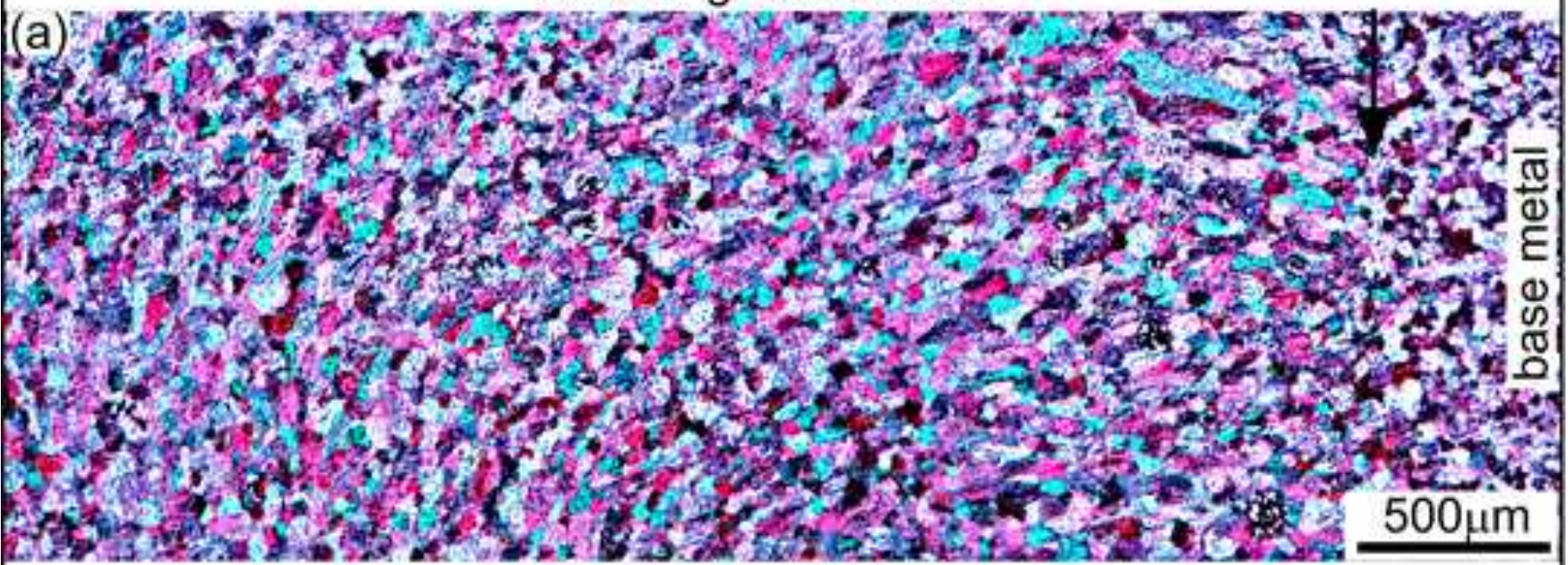

\section{AZ31 Mg: $3.18 \mathrm{~mm} / \mathrm{s}$}

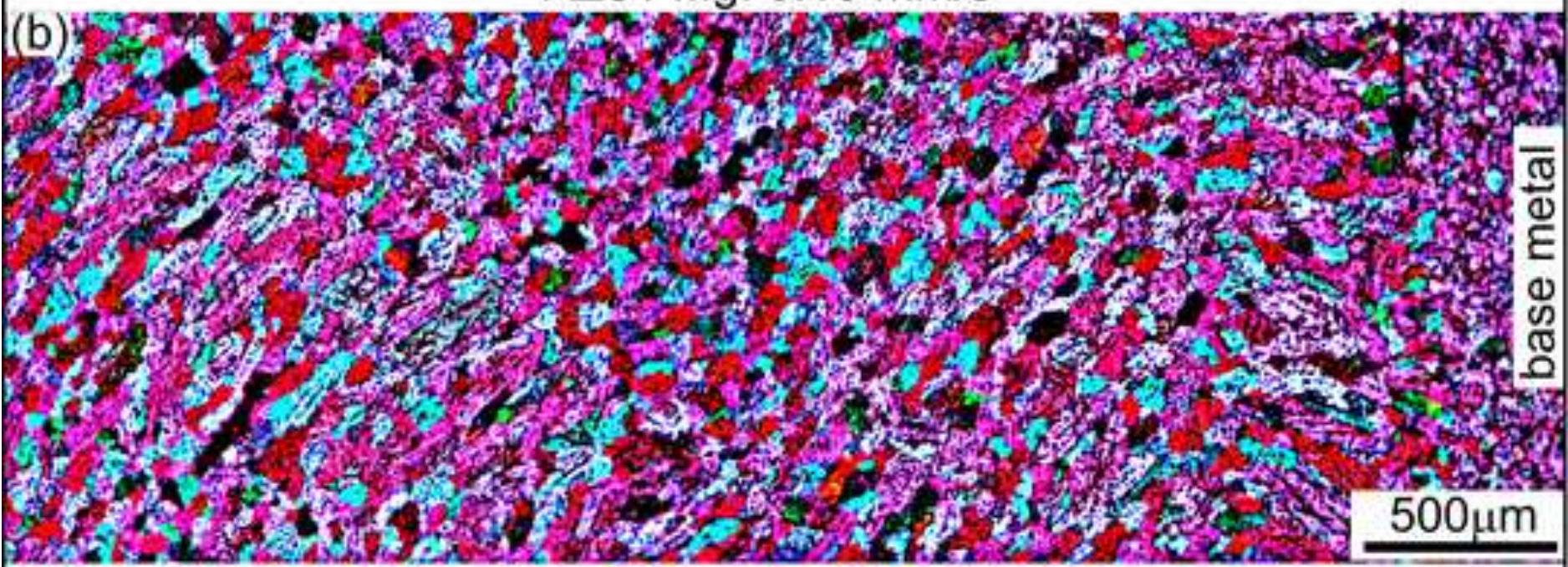

\section{AZ31 Mg: $4.23 \mathrm{~mm} / \mathrm{s}$}

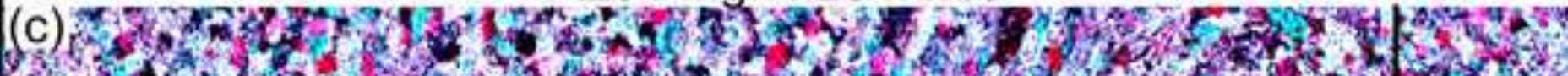
W. 0 W

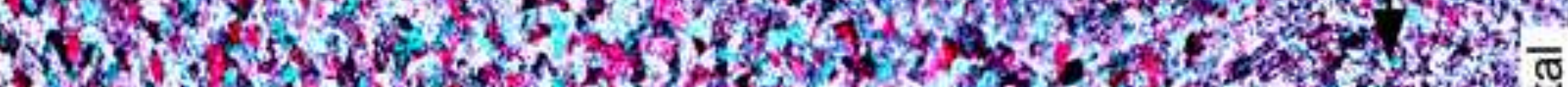

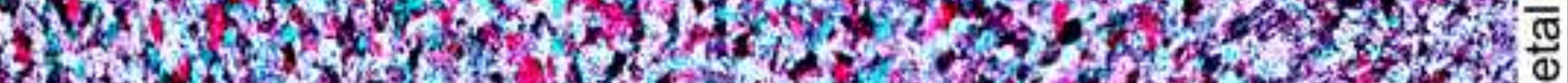

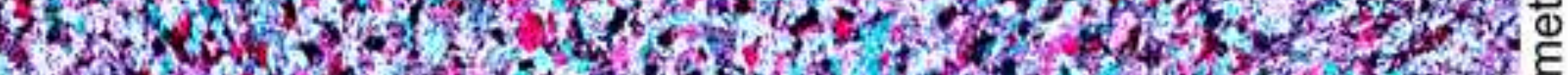

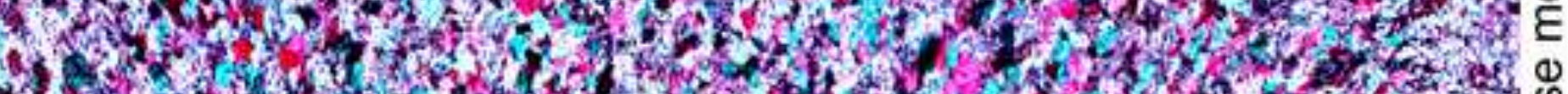

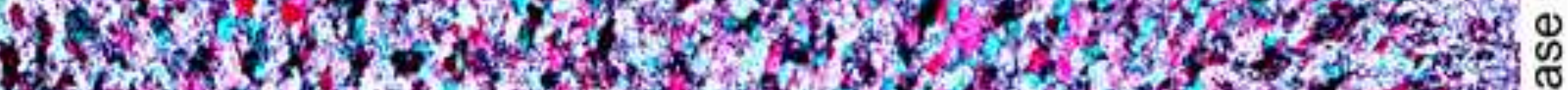

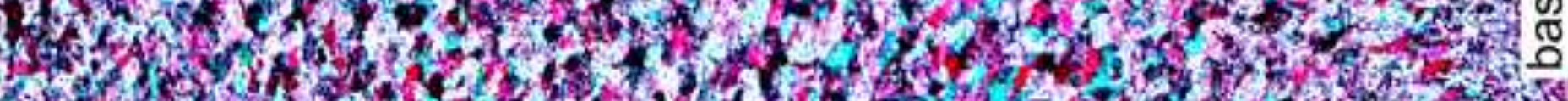

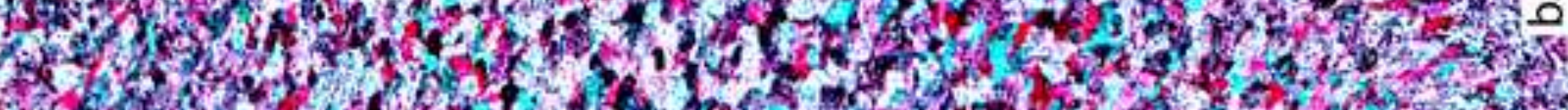

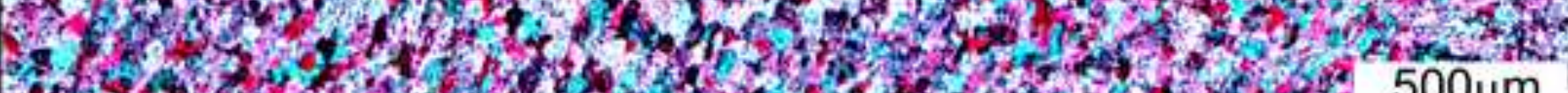

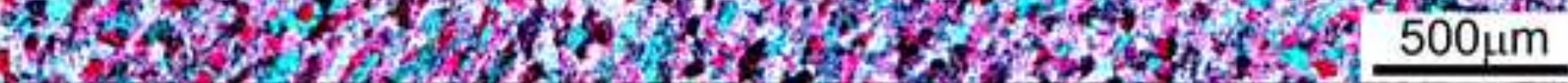




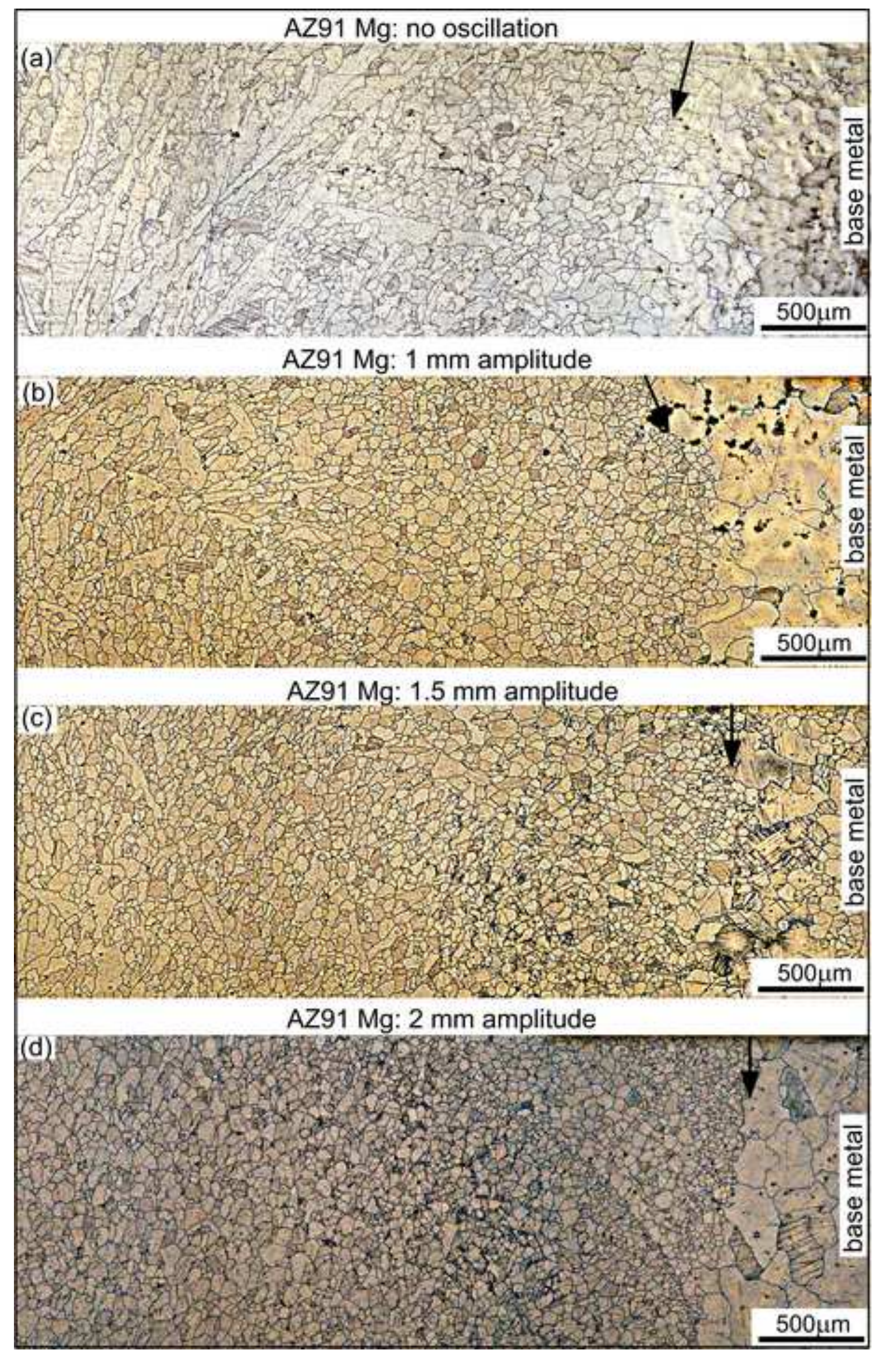




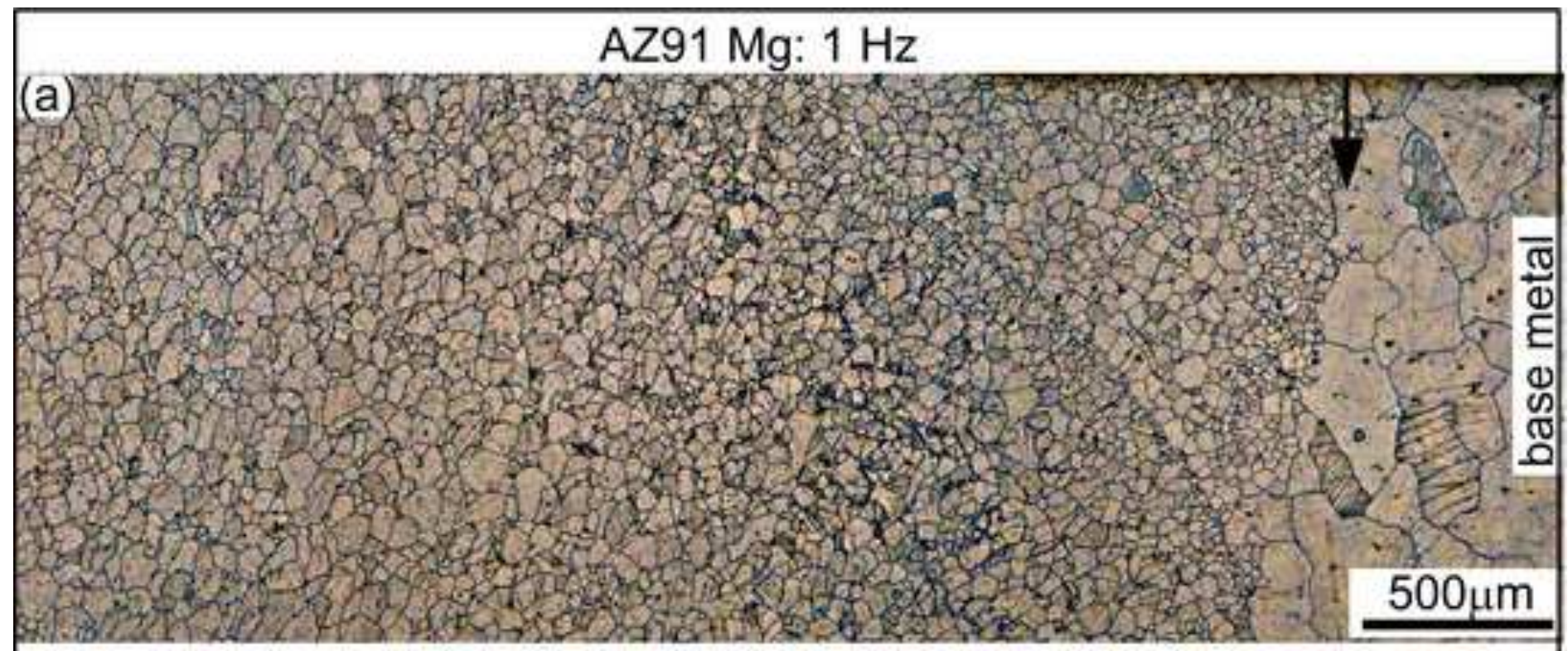

AZ91 Mg: $13 \mathrm{~Hz}$ (b)

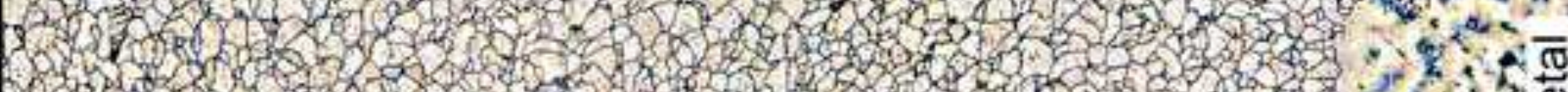

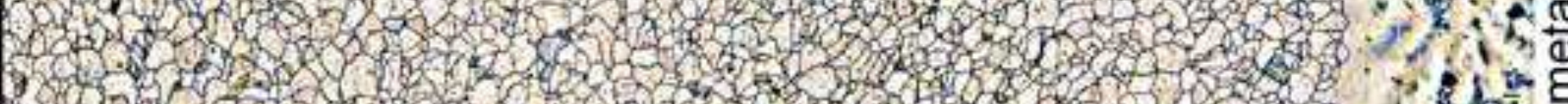

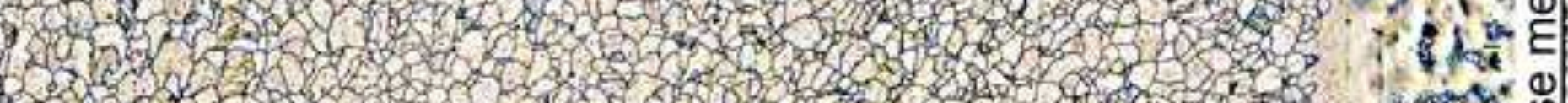

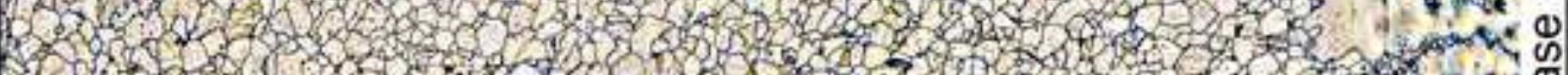

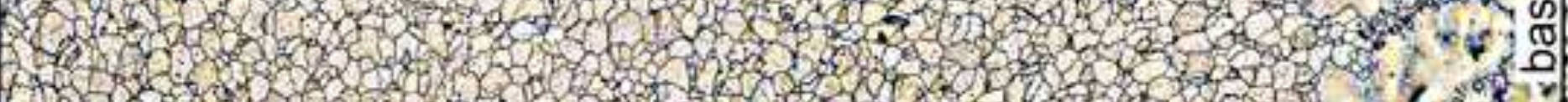

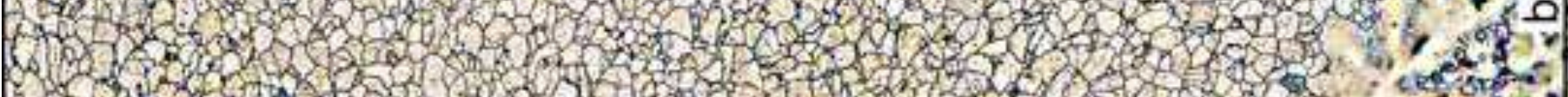

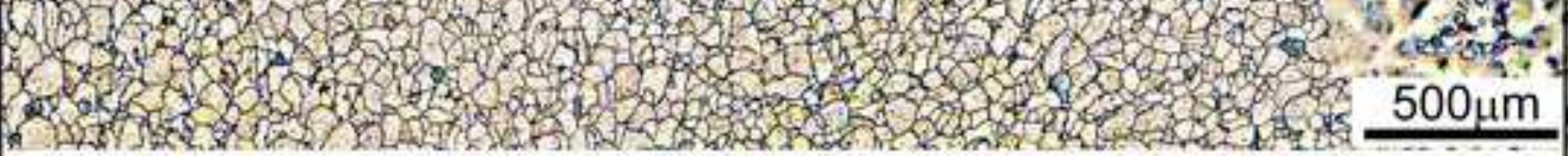

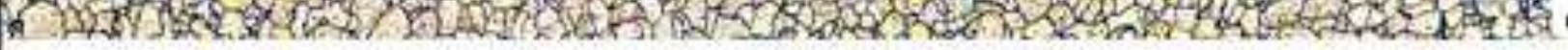

\section{AZ91 Mg: $50 \mathrm{~Hz}$}

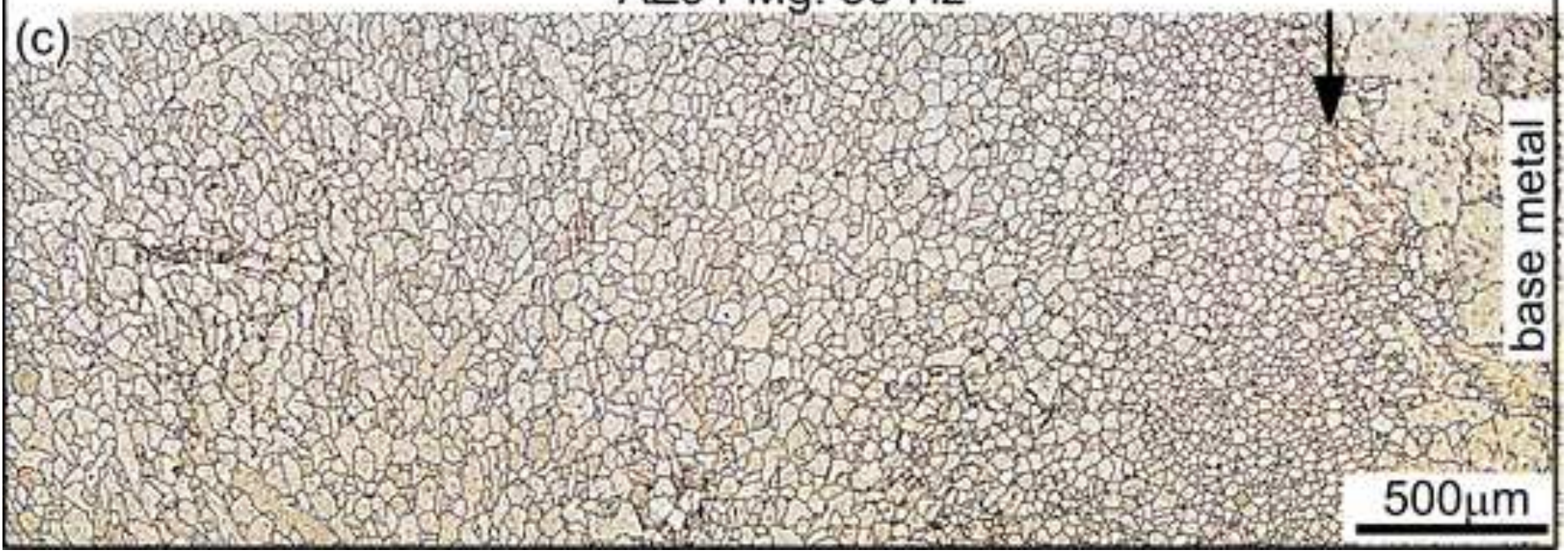




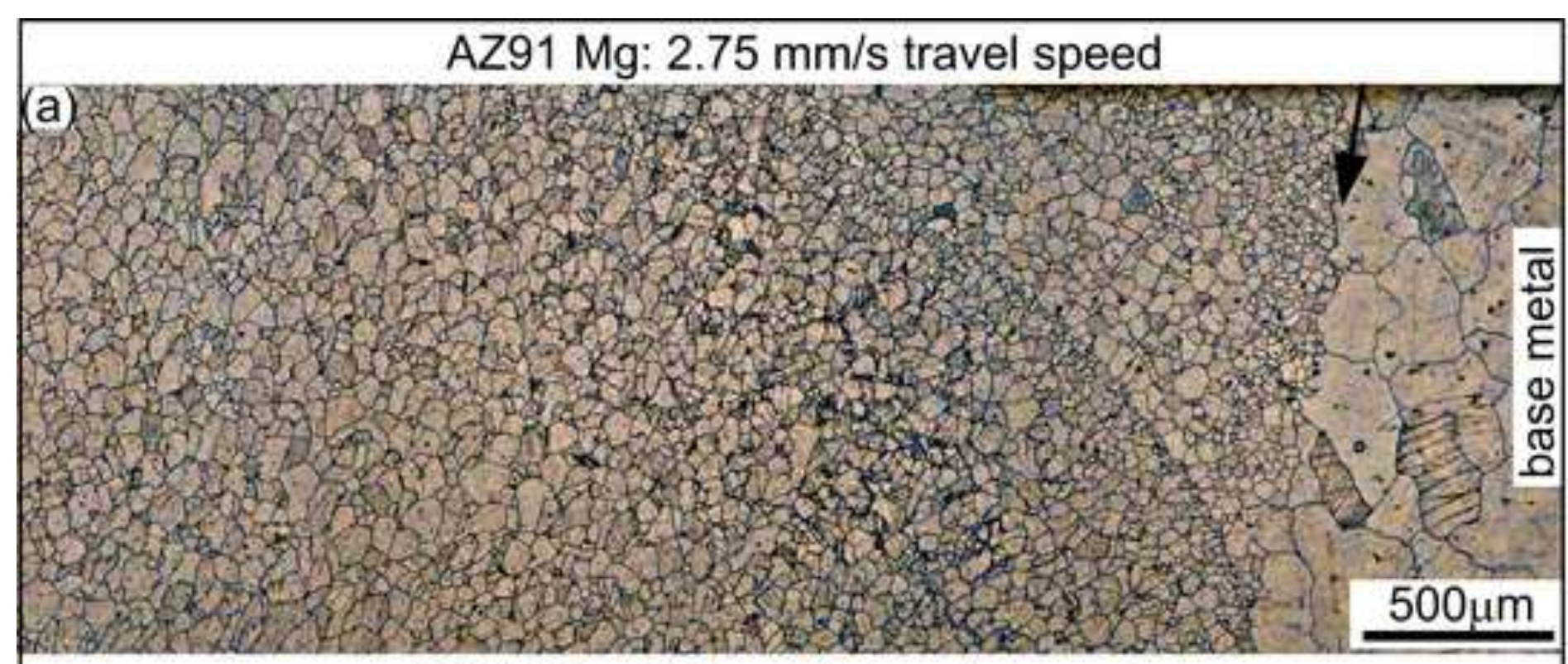

AZ91 Mg: $4.23 \mathrm{~mm} / \mathrm{s}$ travel speed

(b) ${ }_{2}$, w

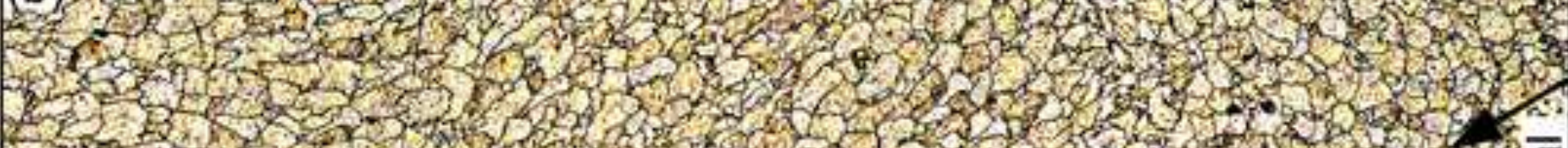

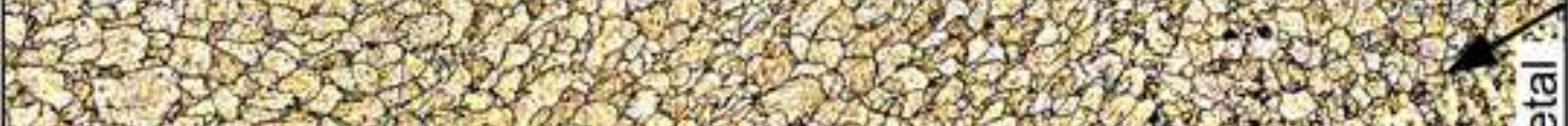

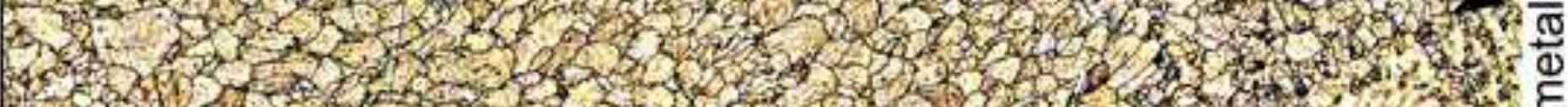

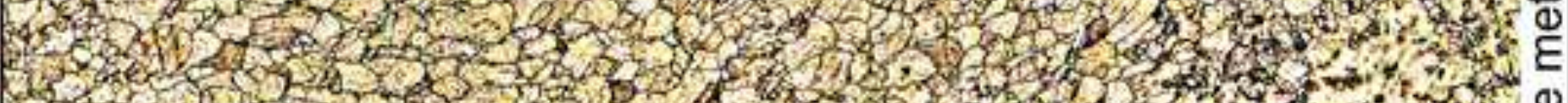

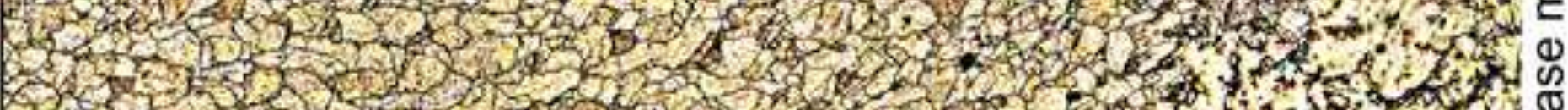

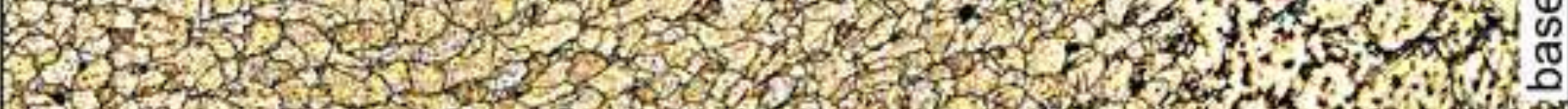

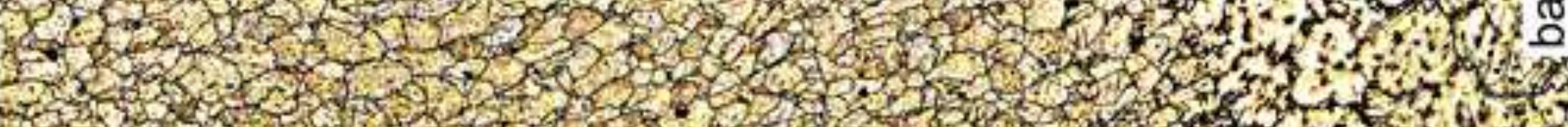

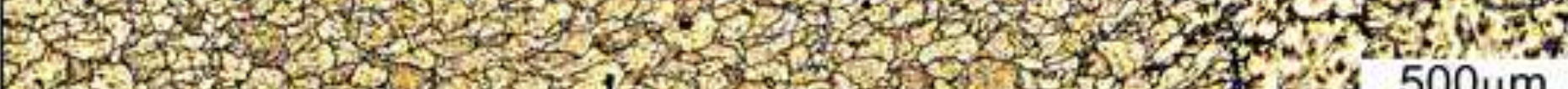

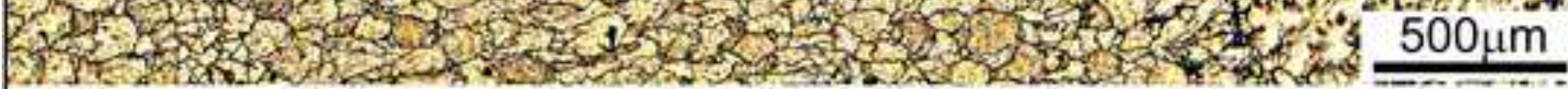

\section{AZ91 Mg: $6.35 \mathrm{~mm} / \mathrm{s}$ travel speed}

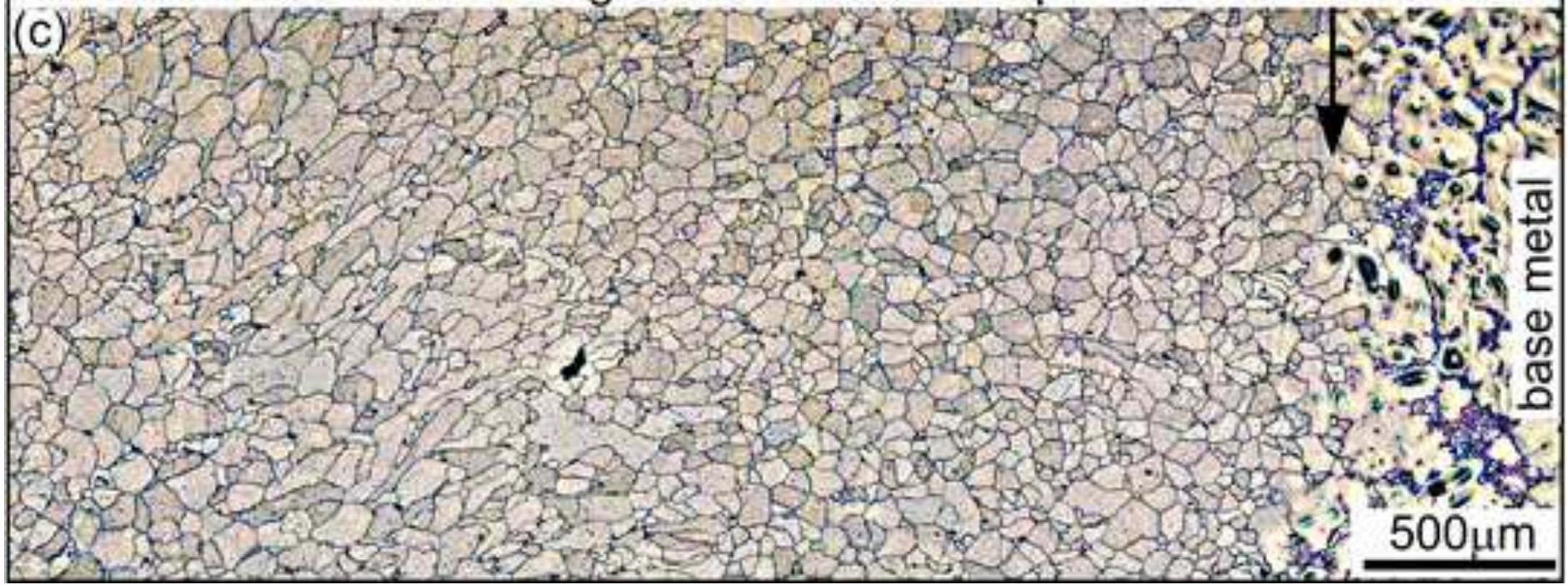




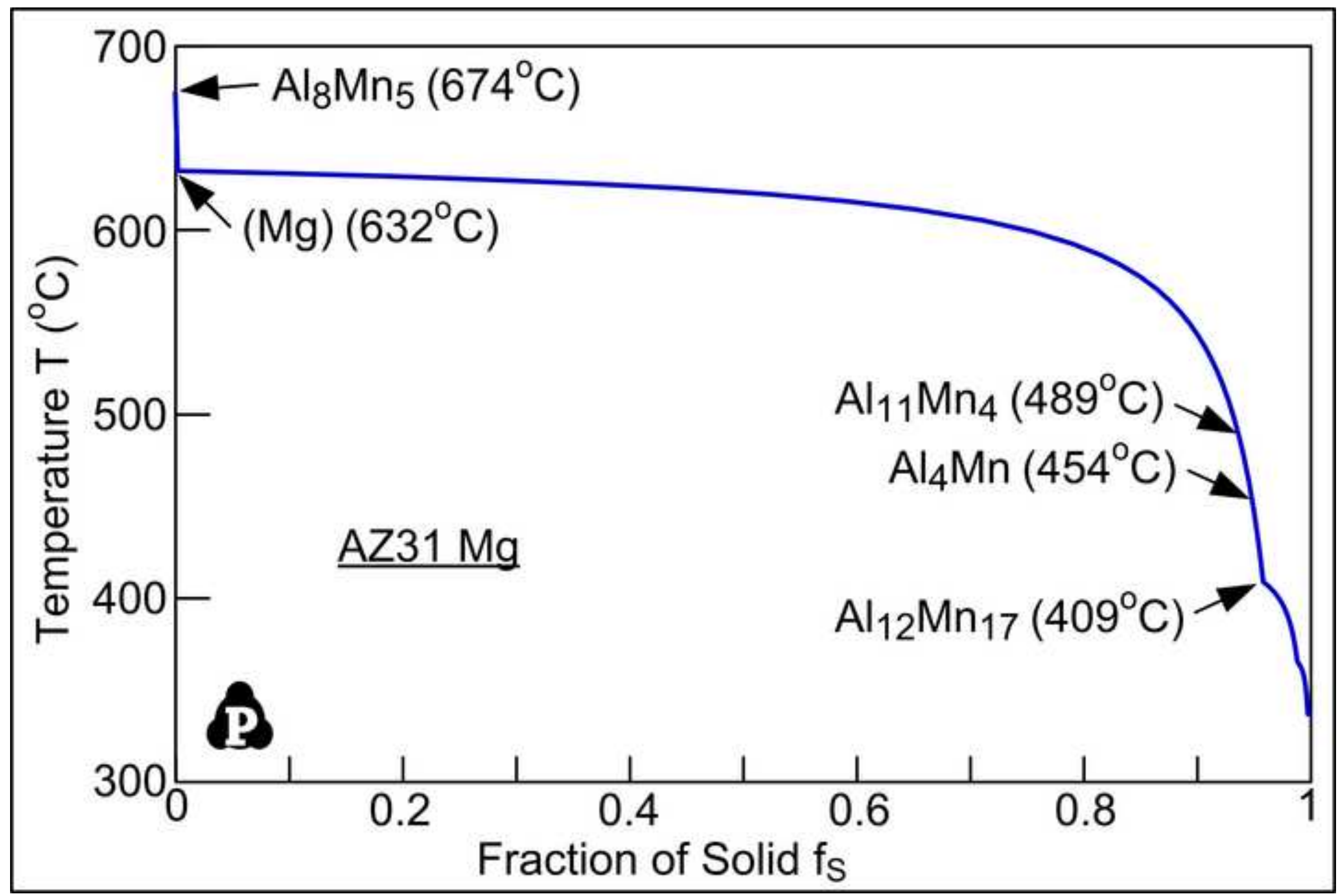


AZ31 Mg test weld \#19 (1 Hz/2 mm) outside preweld \#18 (1-pass, no oscillation)

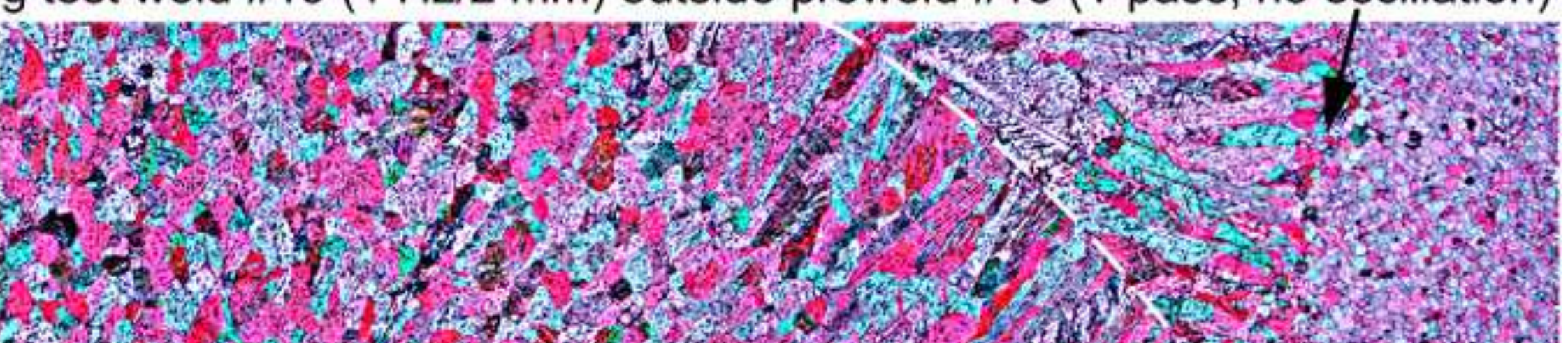

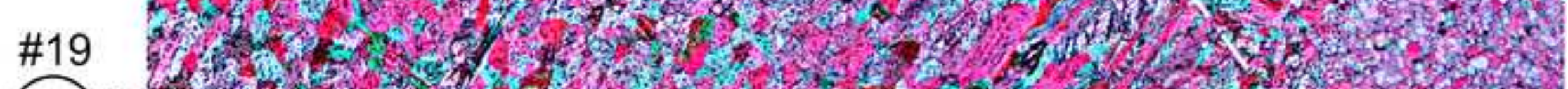

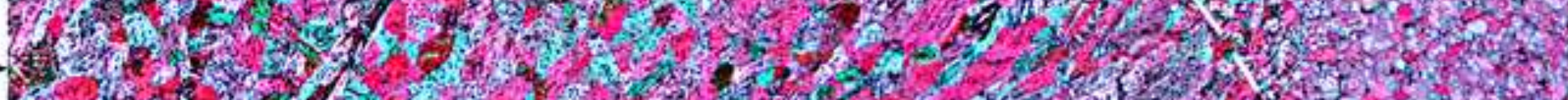

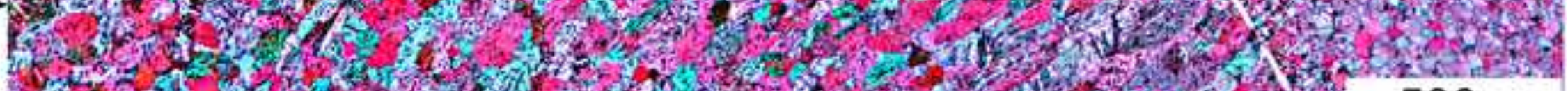

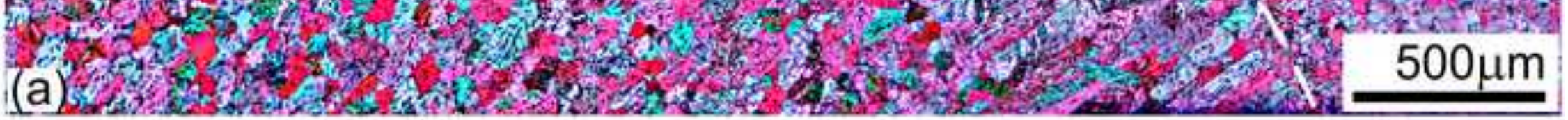

AZ31 Mg test weld \#19 inside preweld \#18

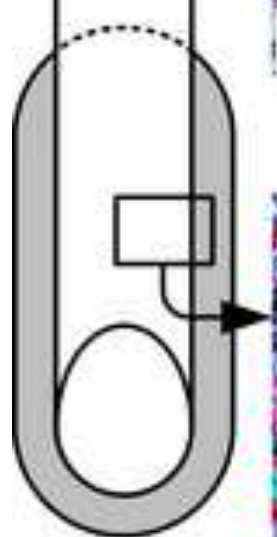

\#18

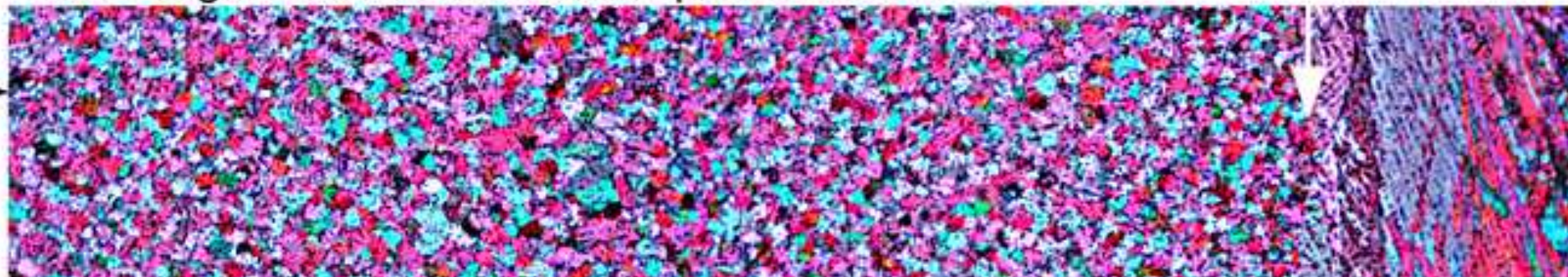

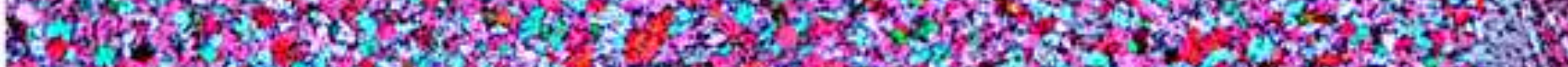

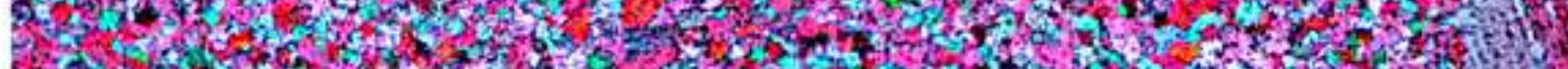

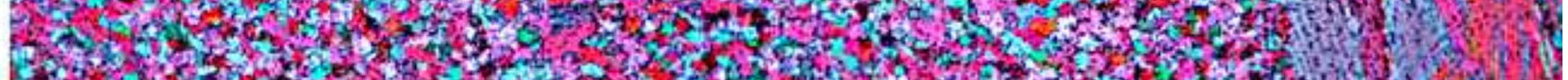

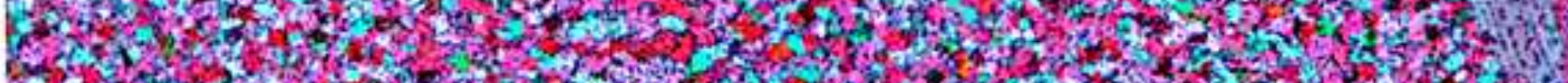

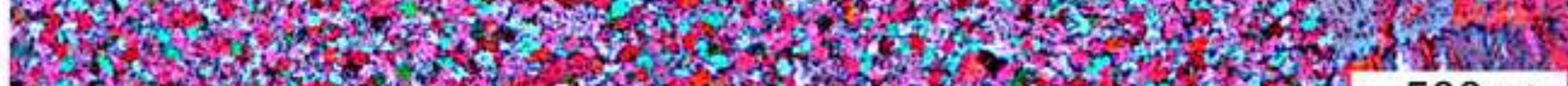

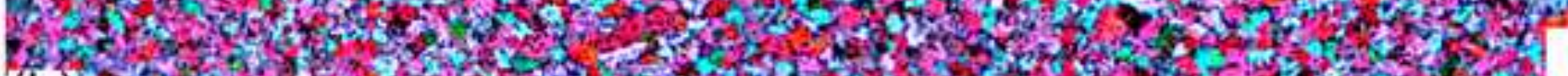
(b) 
AZ31 Mg test weld \#21 ( $1 \mathrm{~Hz} / 2 \mathrm{~mm}$ ) outside preweld \#20 (6-pass, no oscillation)

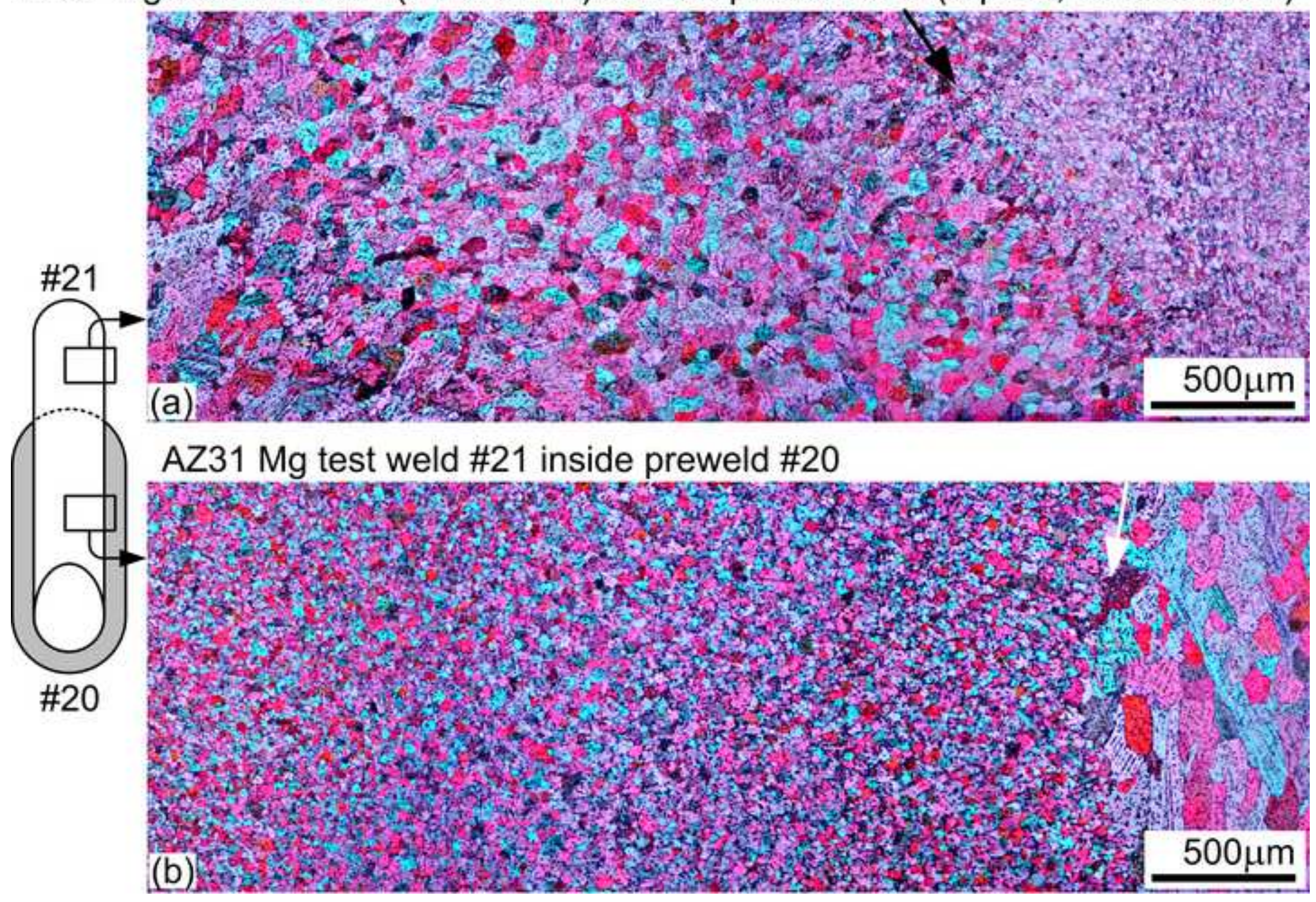




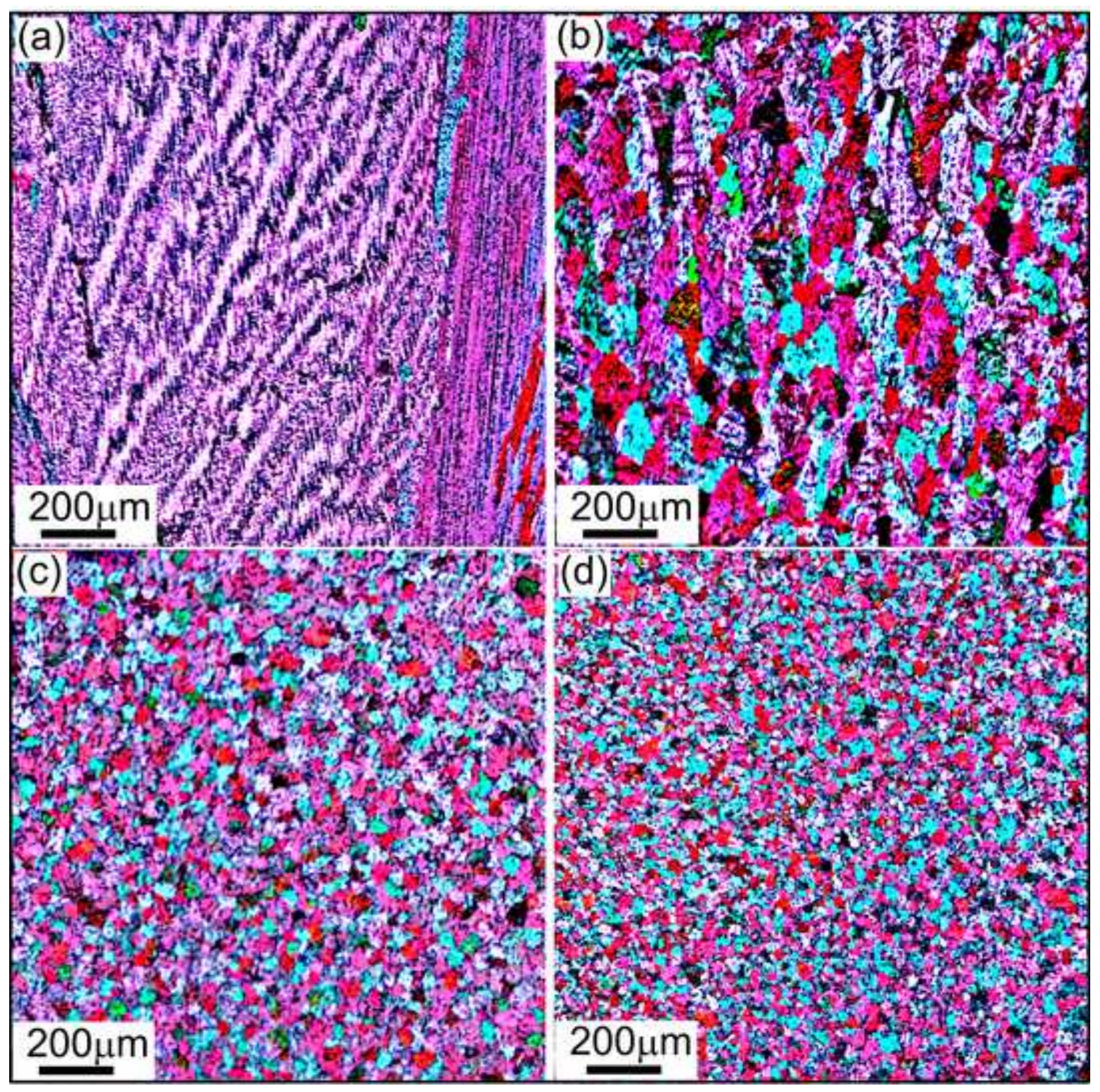




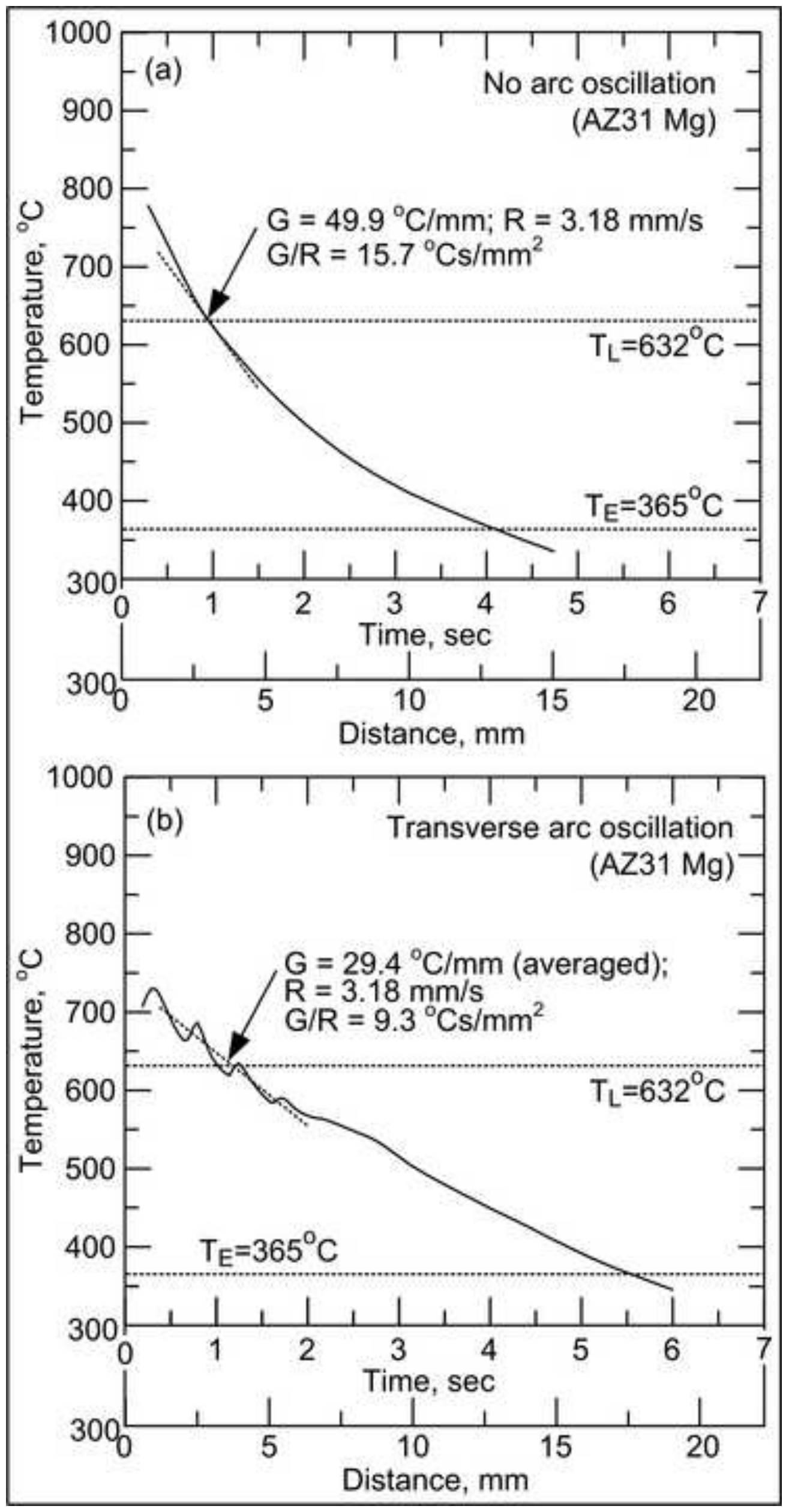




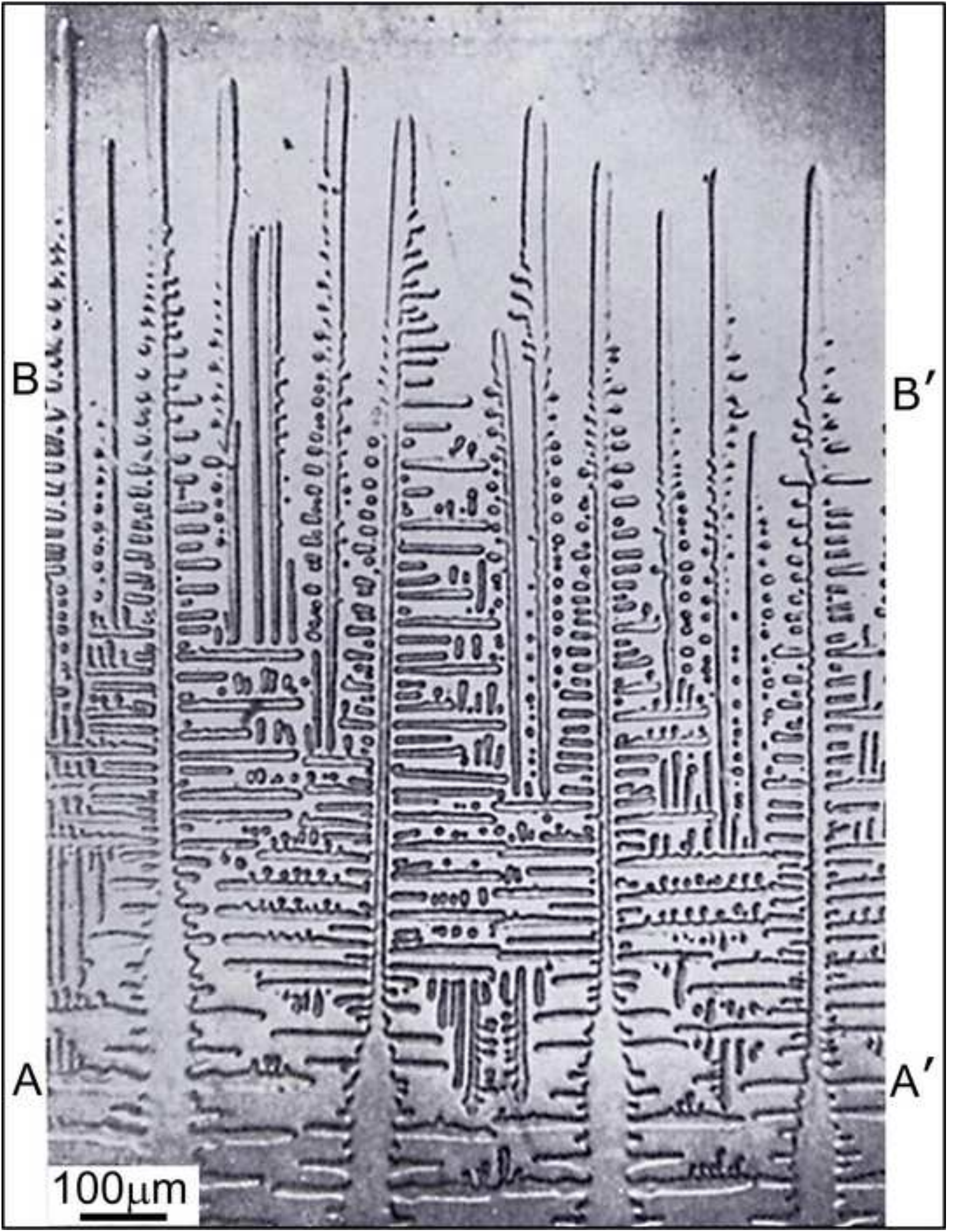




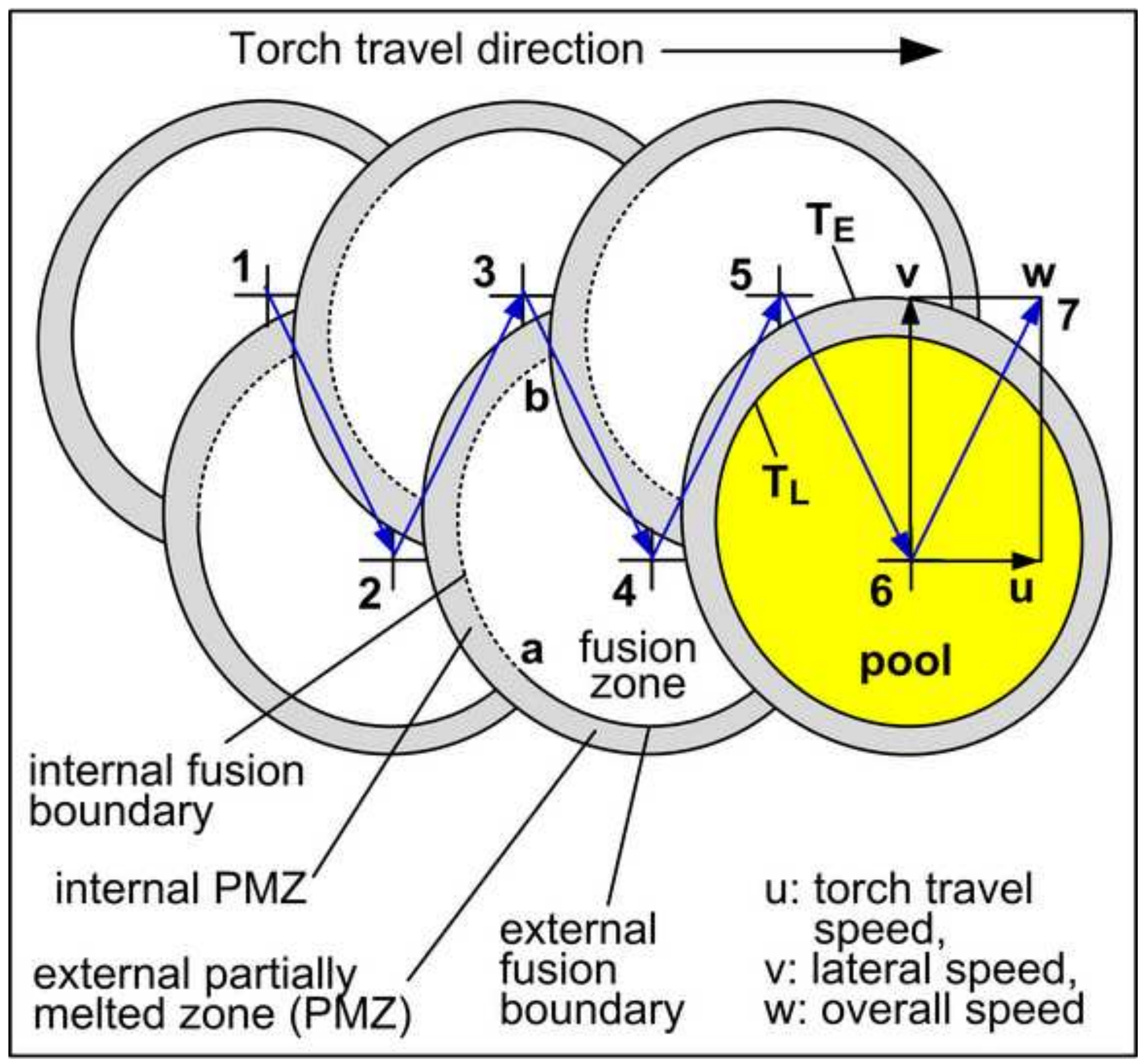




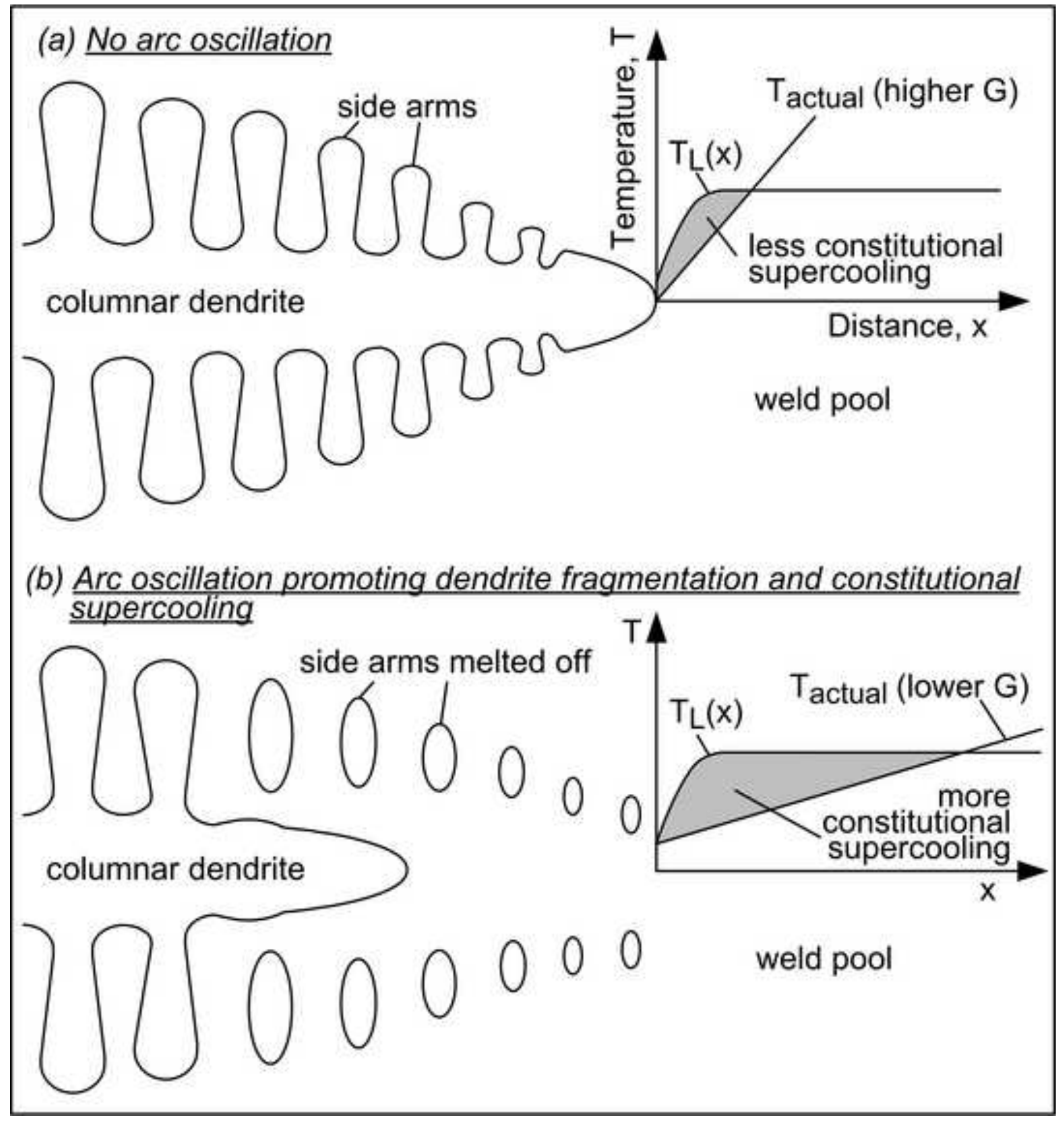




\section{Graphic Abstract}

Grain refining is known to improve the solidification-cracking resistance and mechanical properties of welds. Effective grain refining of $\mathrm{Mg}$ welds was achieved by transverse arc oscillation. The effects of the oscillation amplitude, oscillation frequency and torch travel speed and alloy composition were investigated. The grain refining mechanism was identified as dendrite fragmentation. Cooling curves recorded during weld pool solidification showed transverse arc oscillation caused reheating during solidification, which could in turn cause dendrite fragmentation by remelting the dendrite arms. The curves also showed transverse arc oscillation reduced the cooling rate and hence the temperature gradient $G$ significantly. Thus, transverse arc oscillation also increased constitutional supercooling to help dendrite fragments survive and grow into fine equiaxed grains.
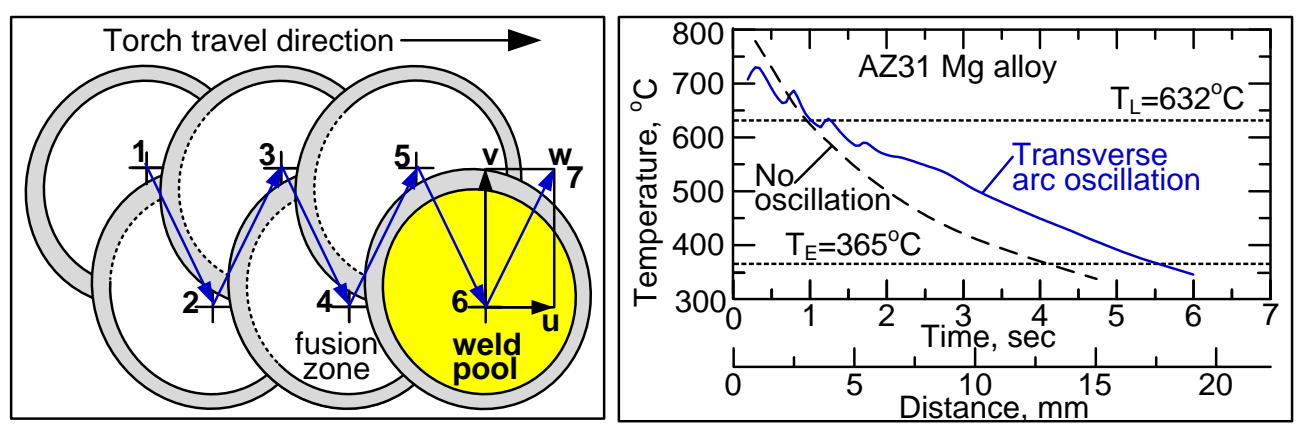

Transverse arc oscillation causing the weld pool to zigzag (left) and the weld metal to experience both reheating (temperature rise) and a reduced temperature gradient as it cools during weld pool solidification (right). 